\title{
WELL-BEING AND MENTAL HEALTH OF UNIVERSITY STUDENTS: UNDERSTANDING THE ROLE OF GENETICS AND SOCIAL BEHAVIOURS
}

\author{
Ajani Asokumar \\ A thesis submitted to the Faculty of Graduate and Postdoctoral Affairs \\ in partial fulfillment of the requirements for the degree of \\ Master of Science \\ in \\ Neuroscience
}

Carleton University

Ottawa, Canada

(C)2015

Ajani Asokumar 


\begin{abstract}
There appears to be variability in the incidence of stress-induced mental health problems among young adults, whereas some readily succumb to the effects of stressors, others appear to be resilient. This resiliency may be attributed to the interaction of psychosocial and genetic factors. The goals of the present study were to examine the relationships between various social behaviours with depressive symptomatology and to assess whether these relationships were related to genotype of a neuropeptide Y (NPY) polymorphism, rs16147. Carleton University first-year undergraduates $(N=126)$ of Euro-Caucasian descent completed questionnaires and provided saliva samples for genotyping. Relationships were found between social support, unsupport, social connectedness, feelings of loneliness, and psychological well-being with depressive symptoms, which were moderated by NPY genotype. These data suggest that the NPY polymorphism interacts with psychosocial adversity in predicting depressive symptoms in young adults, supporting the potential buffering effects of NPY in relation to stress-inducing outcomes.
\end{abstract}




\section{Acknowledgements}

First and foremost, I owe my supervisor, Dr. Hymie Anisman, a debt of gratitude for his invaluable support and guidance throughout this endeavor. I have learned a great deal from Dr. Anisman, both academically and professionally, and look forward to his continued direction and insight over the remainder of my graduate studies. I would also like to thank my committee members, Dr. Alfonzo Abizaid and Dr. Michael Hildebrand for their time and input on my thesis. Further, I am grateful to the other members of Dr. Anisman's lab for their continuous assistance throughout this entire process. Lastly, words cannot express my heartfelt appreciation for my parents, sister, and fiancé as I could not have made it to this point without their unconditional love and encouragement each step of the way and so to them, I dedicate this thesis. 


\section{Table of Contents}

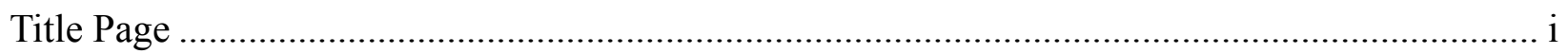

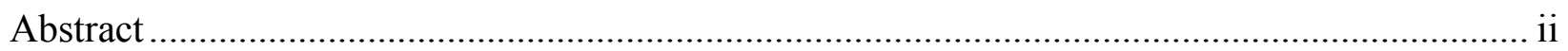

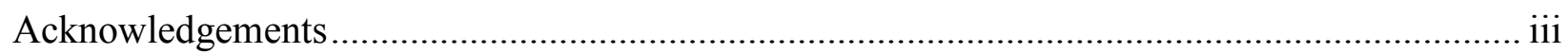

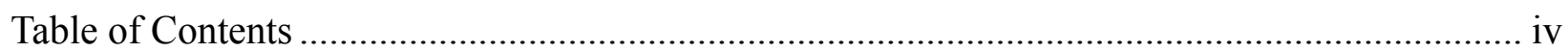

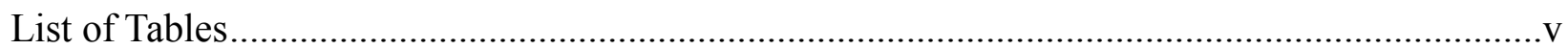

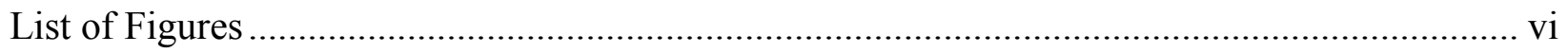

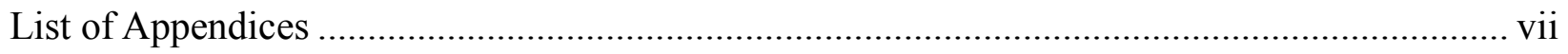

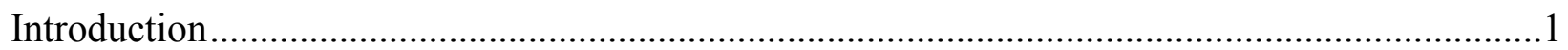

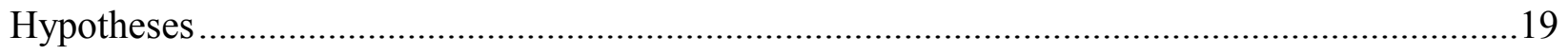

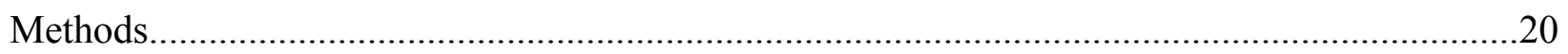

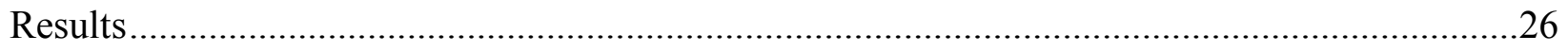

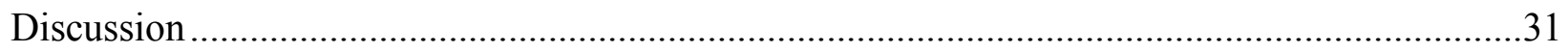

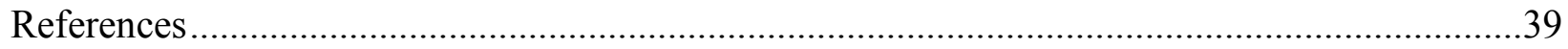

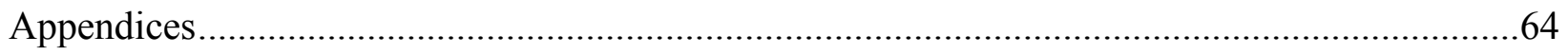




\section{List of Tables}

Table 1. NPY rs16147 gene polymorphism distributions by ethnicity $(n=248)$

Table 2. Bivariate correlations depicting relations between depressive symptoms, overall psychological well-being, social support, social connectedness, unsupport, and loneliness. $(n=251)$

Table 3. Bivariate correlations depicting relations between depressive symptoms and the six subscales of psychological well-being. $(n=251)$ 


\section{List of Figures}

Figure 1. The relation between psychological well-being and depression scores as a function of the NPY genotype (AA vs. AG/GG).

Figure 2. The relation between social support and depression scores as a function of the NPY genotype (AA vs. AG/GG).

Figure 3. The relation between unsupport from friends and depression scores as a function of the NPY genotype (AA vs. AG/GG).

Figure 4. The relation between (A) social connectedness and (B) loneliness with depression scores as a function of the NPY rs16147 genotype (AA vs. AG/GG; $n=126$ ). 


\section{List of Appendices}

Appendix A Recruitment Notice

Appendix B Informed Consent

Appendix C Written Debriefing

Appendix D Background Information Appendix E Beck Depression Inventory Appendix F Additional Debriefing

Appendix G. Suicide Ideation Protocol

Appendix H. Ryff's Well-Being Scales Appendix I Social Connectedness Scale - Revised Appendix $\mathbf{J}$ The Social Provisions Scale Appendix K. Unsupportive Social Interactions Inventory Appendix L UCLA Loneliness Scale 


\section{Introduction}

The transition from adolescence to early adulthood is marked by the emergence of novel stressors that can be particularly challenging. Many young adults feel pressured by the precipitous increase in academic, vocational, and economic responsibilities (Zarrett \& Eccles, 2006). For some, these feelings can be exacerbated when moving away from home and from an established network of family and friends (Lenz, 2001). The combination of increased obligations and sudden autonomy may particularly impact the psychological well-being and mental health of post-secondary students (Adlaf, Gliksman, Demers, \& Newton-Taylor, 2001; Dyrbye, Thomas, \& Shanafelt, 2006; Roberts, Golding, Towell, \& Weinreb, 1999). Indeed, the prevalence of levels of distress, anxiety, and depressive symptoms is particularly high among university students (Adlaf et al., 2001; Mahmoud, Staten, Hall, \& Lennie, 2012; Sax, 1997; Webb et al., 1996). There is clearly appreciable variability concerning the incidence of mental health problems among these individuals. Whereas some readily succumb to the effects of stressors, others are seemingly resilient, being able to manage to overcome their initial distress or to appear unaffected at all. There are likely multiple factors that contribute to resiliency, including psychosocial, environmental, as well as genetic factors (Cohen \& Wills, 1985; Feder, Nestler, \& Charney, 2009; Herbert \& Cohen, 1993).

Several candidate genes have been identified that are potentially linked to stress-related processes as well as major depressive disorder. In this regard, polymorphisms related to neuropeptide Y (NPY) have been identified that may promote or act against psychological disorders (Domscheke et al., 2010; Heilig et al., 2004; Sjohom, Melas, Forsell, \& Lavebratt, 2009; Zhou et al., 2008). The impact of a polymorphism on psychopathology could occur because of interactions with (or actions on) psychosocial or environmental factors. These 
include, among others, the perception of social support, as well as the support received from social ties with individuals, groups and the overall community in the form of psychological, physical, financial, or informational assistance (Haslam, O’Brien, Jetten, Vormedal, \& Penna, 2005). These supportive behaviours seemingly counteract and buffer against pre-existing environmental and genetic vulnerabilities to stress (Ozbay et al., 2007; Rook, 1987). It might similarly be the case that genetic factors act together with unsupportive social interactions, or actions that directly undermine or minimize an individual's stressors and problems (Davis, Brickman, \& Baker, 1991; Song \& Ingram, 2002).

Given these facets, the present investigation (1) examined whether there are relationships between various social behaviours (i.e., supportive and unsupportive social interactions, social connectedness, and feelings of loneliness) and psychological well-being with depressive symptomatology in first year university students and (2) assessed whether these relationships are related to genotype (i.e., NPY polymorphism).

\section{Depression}

Major depressive disorder (MDD) is characterized by a melancholic mood and anhedonia, the inability to feel pleasure, and is accompanied by various other symptoms, such as weight and appetite changes, sleep disturbances (e.g., insomnia or hypersomnia), change in activity, loss of energy, feelings of worthlessness or excessive guilt, diminished cognitive abilities, and reoccurring suicidal thoughts (American Psychiatric Association, 2013). The lifetime prevalence of depression among Canadians is approximately $16 \%$ among women and $11 \%$ in men (Health Canada, 2009) and is notably higher among young adults, aged 15 to 24 (Canadian Mental Health Association, 2015). Over 50\% of depressed patients experience one or more episodes and the recurrence rate increases by as much as $80 \%$ after multiple episodes 
(American Psychiatric Association, 2000; Kupfer, Frank, \& Wamhoff, 1996; Post, 1992). Indeed on average, depressed patients may experience between five and nine depressive episodes during their lifetime (Kessler \& Walters, 1998; Kessler, Zhao, Blazer, \& Swartz, 1997). Furthermore, minor depression, characterized as not fulfilling the diagnostic criteria for major depression, affects quality of life and is highly predictive of subsequent development of major depression (Beekman et al., 1995; Cuijpers, de Graaf, \& van Dorsselaer, 2004; Judd, Akiskal, \& Paulus, 1997). When factoring in the prevalence of minor and subsyndromal depression, the overall incidence of depressive symptoms is much higher. Of note, $15-20 \%$ of Canadian undergraduate students presented with these subsyndromal symptoms and moreover, $30 \%$ reported elevated psychological distress not otherwise seen among the general population (Adlaf et al., 2001). Major depressive disorder is the second leading cause of disability worldwide and a major contributor to the burden of suicide (Ferrari et al., 2013). In fact, the comorbidity of MDD and suicide is approximately 10-15\% (Mann, 2003; Mann et al., 1999;) and strikingly, suicide attempts are greater among adolescents, particularly those presenting with depressive symptoms (Keith, 2001; Shafii, Steltz-Lenarsky, Derrick, Beckner, \& Whittinghill, 1988; Zametkin, Atler, $\&$ Yemeni, 2001). Furthermore, depressive symptomatology accounts for a large economic burden due to increased utilization and costs of medical services, lost work productivity, and suicide-related costs (Stoudemire Frank, Hedemark, Kamlet, \& Blazer, 1986; Wang, Simon, \& Kessler, 2003). These issues highlight the importance of recognizing depressive symptoms and understanding the causes for this mood disorder in order to administer successful treatment.

\section{Stress and Depression}

Depressed patients often report experiencing a greater number of life stressors prior to the onset and recurrence of their depressive episodes (Brown \& Harris, 1989; Hammen, 2005; 
Mazure, 1998). In fact, $80 \%$ of depressed individuals had recently experienced major life events and in comparison to non-depressed controls, life stressors were 2.5 times more likely among depressed patients (Mazure, 1998). It is evident that there may be a relationship between the experience of stressors and the onset of depression, however, not every individual who experiences a negative life stressor becomes depressed. One explanation is that certain life stressors may be perceived as more stressful than others (Mazure, 1998). For example, interpersonal-related stressors, particularly the experience of loss (e.g. bereavement, separations, or threats of separation), may be more predictive of depressive symptoms (Kendler et al., 2010; Paykel \& Cooper, 1992; Paykel, 2003; Tennant, 2002). Moreover, life stressors can be categorized as being independent events that are out of a person's control, or dependent events to which a person directly contributed. It appears that dependent stressors, such as interpersonal events and other sources of self-esteem (e.g. work and finances), are more predictive of major depression (Hammen, 1991; Kendler, Karkowski, \& Prescott, 1999).

The experience of chronic stress, defined as more enduring, major adverse circumstances (Avison \& Turner, 1988; Breslau \& Davis, 1986), may also be a predictor of depressive symptomatology and may even be more strongly related to the onset of depressive episodes than the experience of acute stress (Breslau \& Davis, 1986; McGonagle \& Kessler, 1990). In fact, patients were more likely to have experienced at least one severe life stressor (e.g. poverty, medical disabilities, and lasting martial conflict) prior to onset of depression (Brown \& Harris, 1978; Bruce \& Hoff, 1994; Dohrenwend et al., 1992; Murphy et al., 1991; Swindle, Cronkite, \& Moos, 1989). Likewise, chronic stressors related to intimate relationships, close friendships, family relations, finances, and the health of self and loved ones were more predictive of depression in patients (Hammen, 1992) as well as in youth at risk for depression (Hammen, Shih, 
\& Brennan, 2004). It seems that the causal direction between chronic stressors and depression is difficult to determine and instead, there appears to be a functional relationship between chronic and episodic stressors with depression (Hammen, 2005). Chronic stressors may provoke depressive disorders, but at the same time depressive illness may be a chronic stressor so that the depression builds upon itself (e.g., through rumination; Nolen-Hoeksema, Parker, \& Larson, 1994). Furthermore, chronic stressors may worsen the negative effects of acute stressors on depression, and acute life stressors may heighten the depressive consequences of chronic events (Brown \& Harris, 1978; Cabib \& Puglisi-Allegra, 1996; McGonagle \& Kessler, 1990).

The impact of long-term or repeated stressors may also cause inter-individual vulnerability to depression due to allostatic overload, wherein the wear and tear on biological processes leads to pathological outcomes (McEwen, 2000, 2004). Over time, repeated experience of stressors can trigger and accelerate disease processes, such as the onset and progression of depressive episodes (McEwen, 2000, 2006). This may be explained by sensitization to the effects of chronic events in that individuals may become more easily affected by repeated stress exposure. Consequently, after repetitive chronic stress, those who originally required greater stressor exposure for a depressive episode to occur, may exhibit depressive symptoms even in response to mild stressors that might otherwise seemed to be insignificant (Post, 1992; Post, Rubinow, \& Ballenger, 1984).

Aside from the type of stressors, differences in susceptibility to depression may be due to differential impact based on individual vulnerability, as some readily succumb to the effects of stressors, whereas others are seemingly resilient, being able to manage to overcome their initial distress or to appear unaffected at all (Mazure, 1998). Additionally, there may be subtypes of individuals who are at high risk so that even minor negative events may induce depressive 
symptoms (Mazure, 1998; Nelson \& Charney, 1980). These inter-individual differences highlight the need to understand the neurobiology of stress resilience and the factors that moderate this.

\section{Neurobiology of Stress Resilience}

Psychological resilience usually refers to the ability to overcome illness, but has also been defined to include the ability to adapt to stress and hardships and hence the preclusion of subsequent illness (Anisman, 2015). There are likely multiple elements that contribute to resiliency, including neurobiological, genetic, and psychosocial factors (Cohen \& Wills, 1985; Feder et al., 2009; Herbert \& Cohen, 1993; Lesch, 2004).

The HPA axis plays a role in the stress response. Upon exposure to a stressor, aspects of the prefrontal cortex engage in appraisals of this stimulus, which might then promote activation of the paraventricular nucleus of the hypothalamus, and hence secretion of corticotropinreleasing factor $(\mathrm{CRF})$, which triggers the anterior pituitary gland. The resulting release of adrenocorticotropin hormone (ACTH) stimulates glucocorticoid release from the adrenal gland as well as dehydroepiandrosterone (DHEA). Glucocorticoids, specifically cortisol in humans, have a variety of functions including increased arousal, immune response inhibition, glucose release for energy as well as interaction with various neurotransmitters and brain systems (Del Ray, Chrousos, \& Besedovsky, 2008).

Patients who are depressed often have hyperactive HPA axis responses reflected by elevated CRH, ACTH, and cortisol levels (Hasler, Drevets, Manji, \& Charney, 2004). Of the stress response hormones, $\mathrm{CRH}$ has been implicated in the provocation of adverse events. Administration of CRH causes hypertension, increased heart rate, increased arousal, decreased appetite, reduced sexual interest, and reduced reward expectations, all of which are also observed in patients with depression (Owens \& Nemeroff, 1991). Furthermore, the negative HPA feedback 
loop has been found to be impaired in some depressed patients, thus, augmented levels of cortisol do not inhibit the response and instead there is continuous stimulation of the HPA axis (Blackburn-Munro \& Blackburn-Munro, 2001). The hyperactive HPA activity can lead to disturbances in neurotransmitter release, immunosuppression, hypertension, dyslipidemia, osteoporosis, and brain disturbances, such as hippocampal cell loss (Checkley, 1996;

Karlamangla et al., 2002; Sapolsky, 2003). Thus, factors that buffer the HPA response or help to end the response in a timely matter may bolster resilience to the effects of stressors.

Upon secretion of ACTH, adrenal DHEA is released alongside cortisol. This adrenal steroid may have neuroprotective qualities as it has anti-glucocorticoid and anti-glutamatergic effects (Charney, 2004). For example, DHEA is negatively correlated with depression and has anti-depressant-like effects in individuals with MDD (Goodyer, Herbert, \& Altham, 1998; Wolkowitz et al., 1999). Moreover, women with PTSD displayed more severe symptoms when DHEA levels were diminished (Rasmusson et al., 2004). In addition, a positive relationship was found between the DHEA/cortisol ratio and performance of soldiers during high stress-inducing training, a further possible indication of psychological resilience (Morgan et al., 2004).

Possessing the capability to be resistant to fear conditioning may also bolster stress resilience (Ozbay, Fitterling, Charney, \& Southwick, 2008). The amygdala and hippocampus are thought to be involved in fear conditioning and have been implicated in anxiety as well as mood disorders due to hyperactive fear-induced responses (Maren, 2001; Rosen \& Schulkin, 1998; Wolpe, 1981). For instance, depressed subjects displayed enlarged amygdala volume (Frodl et al., 2002; Lange \& Irle, 2004; Sheline, Gado, \& Price, 1998), abnormal resting amygdala blood flow, and impaired functioning during emotional tasks that involve the amygdala (Abler, Erk, Herwig, \& Walter, 2006). Thus, maintaining optimal activation of the amygdala and the ability to 
extinguish fear-induced responses may contribute to resilience against depressive symptomatology (Ozbay et al., 2008).

In addition to the amygdala, stressors appear to have a strong influence on neuronal activity within the hippocampus (Peters, 2006), which is involved in learning and memory, including memory of fearful situations. Patients with major depression may display decreased hippocampal volume (Sapolsky, 2001), sometimes reaching 20\% (Bremner et al., 2000; Sheline, Sanghavi, Mintun, \& Gado, 1999), and may account for the loss of cognitive abilities. The hippocampus contains a large number of glucocorticoid receptors, which when overly stimulated may be more vulnerable to the effects of stress. Indeed, persistent and high levels of corticoids can cause damage to CA3 pyramidal neurons, reduce dendritic branching, cause loss of dendritic spines, inhibit new neuronal growth in the dentate gyrus, and reduce excitability of hippocampal neurons (Sapolsky, 2003). Furthermore, the hippocampus plays an important role in the negative feedback and inhibition of the HPA axis, thus hippocampal damage may lead to further hypercortisolism.

There are various pathways and components that are activated in response to stressors. Resiliency to the effects of stressors appears to come from the ability to maintain stress responses. The ability to keep responses within an ideal range, that is, neither too blunted nor excessive, also serves to promote resiliency, and for this to occur requires effective negative feedback functioning. Aside from HPA functioning, there are several other factors that buffer the stress response and contribute to resilience. For the purposes of the present investigation, focus will be placed on the expression of genes related to hormonal processes as well as psychosocial factors, such as supportive and unsupportive social interactions. 


\section{Genetic Factors - Neuropeptide Y}

Many candidate genes have been identified that may potentially link hormonal factors to stress-related processes as well as major depressive disorder (Kauer-Sant'Anna et al., 2007; Rodrigues et al., 2009; Zhou et al., 2008). In this regard, several polymorphisms related to these processes have been identified that may promote or act against psychological conditions and thus contribute to overall well-being and mental health (Domscheke et al., 2010; Heilig et al., 2004; Sjohom et al., 2009; Zhou et al., 2008). One such candidate is neuropeptide Y.

Neuropeptide Y (NPY) is an evolutionarily highly conserved and abundant 36 amino acid neuropeptide. This peptide behaves as a neurotransmitter and is secreted by neurons of the SNS in the autonomic system and by the hypothalamus in the brain. It has been implicated in various functions including appetite and food intake, fat energy storage, blood pressure, circadian rhythms, pain, seizures, hormone secretion, reproduction, hyper tension, and alcohol consumption (Tatemoto, 2004). It also appears to regulate the secretion of several hypothalamic neuropeptides and stimulates the corticotrophic axis (Small et al., 1997). More recently, due to its role in maintaining SNS activity within an optimal range, NPY has also been posited to contribute to mood and anxiety disorders (Ozbay et al., 2008; Southwick et al., 2008; Wu et al., 2011). Indeed, NPY levels in plasma and cerebrospinal fluid (CSF) were lower in depressed patients than in controls (Hashimoto, Onishi, Koide, Kai, \& Yamagami, 1996; Heilig et al., 2004; Hou, Jia, Liu, \& Li, 2006; Widerlov, Lindstrom, Wahlestedt, \& Ekman, 1988). Furthermore, CSF NPY levels were negatively correlated to anxiety scores in clinically depressed patients, indicating a potential role of NPY in anxiety-related depression (Heilig \& Widerlov, 1990; Redrobe et al., 2002). 
Decreased NPY levels may also be linked to suicidality. Between 10-15\% of suicides occur in patients who suffer from depression; suicide has a co-morbidity of up to $60 \%$ with mood disorders (Mann, 2003; Mann et al., 1999). Diminished levels of NPY were found in individuals suffering from some type of mood disorder who had attempted suicide (Westrin, Engstom, Ekman, \& Traskman-Bendz, 1998). Furthermore, plasma NPY levels were lower in individuals who had recently attempted suicide and these decreases were more prominent among individuals who had repeatedly attempted suicide (Westrin, Ekman, \& Traskman-Bendz, 1999). Likewise, reduced amounts of NPY were discovered in post-mortem brain tissue of individuals who died by suicide (Widdowson, Ordway, \& Halaris, 1992).

Many patients with depression exhibit elevated cortisol levels (Brown, Varghese, \& McEwen, 2004), which could be related to NPY (Morgan et al., 2002). In this regard, NPY administration reduced overnight cortisol secretion in healthy participants (Antonijevic et al., 2000). Likewise, when exposed to a stressor, subjects displayed a positive and significant association between NPY and cortisol (Morgan et al., 2002; Morgan et al., 2000). Moreover, it has been suggested that NPY might serve to enhance resilience in response to stressful events. In fact, Special Forces soldiers with higher NPY levels displayed lower levels of distress than did other soldiers (Morgan et al., 2002). This might be due to the high intensity training Special Forces soldiers complete, which may allow for an habituation effect with respect to their stress response, further supporting the buffering effect of NPY. A second possibility is that individuals with increased NPY possess a greater ability to overcome the effects of stress. In essence, NPY may promote resilience to the effects of stressors and may have anxiolytic properties.

Genetic studies have, to an extent, corroborated these findings. An NPY single nucleotide polymorphism (SNP), involving the substitution of Leucine 7 with Proline 7 (Leu7Pro), has been 
identified that appears to be linked to the control of sympathoadrenal, metabolic, and hormonal balance in healthy subjects as those possessing the SNP displayed lower NPY levels as well as lower insulin concentrations, higher glucose concentrations and a higher heart rate (Kallio et al., 2003; Pesonen, 2008). If NPY is related to resilience and protection against stressors, then polymorphisms might account for differences in susceptibility for developing depressive symptoms. In fact, there was greater expression of the Leu7Pro SNP amongst depressed patients relative to controls (Heilig et al., 2004; Sjoholm et al., 2009).

Consistent with these findings, NPY is greatly expressed in limbic system regions, which are responsible for various emotions (Adrian et al., 1983) and in emotional processing in patients with depression (Domschke et al., 2010). Individuals with an NPY polymorphism (rs16147) involving the substitution of adenine (A) with guanine (G), displayed stronger bilateral amygdala activation when shown threatening faces and variation of the SNP accounted for greater emotioninduced activation of the amygdala, both results indicative of a greater stress response (Domschke et al., 2010; Zhou et al., 2008). When under pain or stressor conditions, possession of this particular SNP (i.e. the G allele) predicted decreased resiliency which was measured by stress-induced activation of endogenous opioid neurotransmission in several brain regions (Zhou et al., 2008). Furthermore, upon administration of antidepressants, those with the SNP responded slower to the medication and were more unlikely to achieve remission (Domschke et al., 2010). These results suggest that NPY levels may be predictive of responses to stressors and might act as a buffer to reduce anxiety.

This functional NPY genetic variant (rs16147) is located in the promotor region and is of particular interest as it appears to alter NPY expression in vitro, may account for over half of the variation in NPY expression in vivo, and appears to be involved in transcriptional regulation 
(Itokawa et al., 2003; Shah et al., 2009; Zhou et al., 2008). However, there have been discrepancies regarding the influence of genotype on these processes. For example, individuals with the G allele displayed decreased mRNA expression and in turn, lower levels of NPY, which explained the decreased resiliency as previously mentioned (Zhou et al., 2008). Conversely, individuals with the A allele displayed decreased reporter gene expression, which predicted decreased NPY levels (Buckland et al., 2004; Itokawa et al., 2003). Likewise, post-mortem samples revealed reduced NPY gene expression in individuals carrying an A allele (Sommer et al., 2010). Furthermore, possessing the AA genotype predicted increased risk of post-disaster generalized anxiety disorder (Amstadter et al., 2009). Regardless of these inconsistencies, NPY appears to have anxiolytic properties and NPY SNPs may explain the individual variation in resiliency to stressor-induced symptoms.

The impact of NPY polymorphisms on mental health could occur because of interactions with psychosocial or environmental factors (Ozbay et al., 2007). In fact, animal studies have demonstrated a potential influence of NPY homologs on social feeding (de Bono \& Bargmann, 1998; de Bono et al., 2002), foraging and formation of social groups (Wu et al., 2003), and social interaction (Sajdyk et al., 2008; Thorsell et al., 2006). Although the exact relationship between NPY and social factors is unknown, NPY signalling appears to play a role in social behaviours and together, may contribute to resilience.

\section{Social Support}

Social factors may influence the perception or response to stressful events that, in turn, may affect resiliency (Jackson, Schwab, \& Schuler, 1986; Pearlin, 1993). Social support comprises the support received through social ties with individuals, groups and the overall community in the form of psychological (e.g. emotional support), physical (e.g. contact with 
others), instrumental (e.g. financial support), or informational assistance (e.g. appraisal support) (Haslam et al., 2005; Lin et al., 1979; Ozbay et al., 2008). These supportive behaviours seemingly counteract and buffer against pre-existing environmental and genetic vulnerabilities to stress and may serve as an important stress resilience factor (Cohen \& Wills, 1985; Ozbay et al., 2007; Rook, 1987; Underwood, 2000).

Social support is associated with overall psychological well-being and these effects are most prominent in the context of stressor experiences (Cohen \& Wills, 1985; Turner, 1981). Indeed, social support may act in a protective capacity to diminish stress-related alcoholism (Booth, Russsell, Soucek, \& Laughlin, 1992), arthritis (Penninx et al., 1997), distress related to loss (Catania, Turner, Choi, \& Coates, 1992; Laakso \& Paunonen-Ilmonen, 2002), and cardiac illness (Holahan, Moos, Holahan, \& Brennan, 1995). Furthermore, receiving social support may decrease the amount of medication prescribed to handle various stressors (Cobb, 1976; de Araujo, Dudley, \& Van Arsdel, 1972; de Araujo, Van Arsdel, Holmes, \& Dudley, 1973), enhance treatment compliance, and thus diminish illness relapse (DiMatteo, 2004; Garay-Sevilla et al., 1995; Gonzalez et al., 2004; Hultman, Wieselgren \& Ohman, 1997).

The Social Identity Theory and Self-Categorization Theory suggest that individuals may be protected from negative responses to stressors through social support gained from members of one's social identity (Tajfel \& Turner, 1986; Turner, Hogg, Oakes, Reicher \& Wetherell, 1987; Turner, Oakes, Haslam \& McGarty, 1994). According to the Social Identity Theory, parts of an individual's self-concept results from memberships in relevant social groups (Turner \& Oakes, 1986). Often, people's social identities determine the quality of social connectedness, the number and quality of relationships an individual has with others. In other words, it is a general feeling of belongingness to one's social environment. Individuals with greater social connectedness are 
happier and more successful, contributing to overall well-being and health (Christakis \& Fowler, 2009). The sense of belonging may counteract the effects of stress and anxiety by reducing the negative effects of the neurochemical stress response. In fact, when administered the Trier Social Stress Test for groups (TSST-G), a stress inducing task, participants displayed a decreased cortisol reaction when they were amongst others, indicating a possible stress buffering effect of positive social interactions (Hausser, Kattenstroth, van Dick, \& Mojzisch, 2012). Interestingly, this effect was only present when members shared a group identity. In fact, the impact of social support can depend on the social categorical status (i.e. in-group vs. out-group member) of the individual providing it (Haslam, 2004; Haslam, Jetten, O’Brien \& Jacobs, 2004; Levine, Cassidy, Brazier \& Reicher, 2002). For example, during a mathematical task, students who received informational support from an in-group member experienced a greater positive influence on their stress levels in comparison to those who received support from an out-group member (Haslam et al., 2004).

Poor levels of social support may lead to increased stress responses, such as higher blood pressure, increased heart rate, and increased neuroendocrine responses (Ozbay et al., 2008; Stansfeld, Fuhrer, Head, Ferrie, \& Shipley, 1997; Uchino, Cacioppo, \& Kiecolt-Glaser, 1996) and may thus have negative effects on health. For example, separation and social isolation caused increased heart rates in monkeys, which returned to normal when they were reunited with their social peers (Shively, Clarkson \& Kaplan, 1989). Similarly, during public speaking and mental arithmetic tasks (i.e. TSST), human participants who received social support displayed less pronounced spikes in blood pressure and heart rate as well as lower cortisol levels in comparison to those who had no support, further indicating possible buffering effects (Chen et al., 2011; Kamarck, Annunziato, \& Amateau, 1995; Lepore, Allen, \& Evans, 1993). 
Lack of social support can evoke feelings of loneliness (Rook, 1987). Loneliness is an emotional response and feeling that occurs when one is isolated from others and perceives a lack of companionship. People who experience loneliness often have poor social connectedness and low self-esteem, which may lead to poor adaptive behaviour in response to stressors, which can be a contributing factor to abnormal mental health (Yaacob, Juhari, Talib, \& Uba, 2009). In fact, loneliness, stress, and poor self-esteem have all been found to be predictive of depression, particularly in young adults (Cacioppo et al., 2006; Yaacob et al., 2009), and feelings of loneliness can affect neuroendocrine, cardiovascular, and inflammatory stress responses (Steptoe, Owen, Kuns-Ebrecht, \& Brydon, 2004). For instance, participants with greater feelings of loneliness displayed larger increases in blood pressure and greater fibrinogen levels in comparison to individuals not experiencing loneliness (Steptoe et al., 2004). Moreover, cortisol levels were positively correlated with feelings of loneliness further indicating the harmful effects of isolation on mental and physical health (Steptoe et al., 2004).

Evidently, social support may serve to protect against susceptibility to depressive symptoms. Indeed, a lack of social support has often been associated with depression and possible relapse (Cairney, Boyle, Offord, \& Racine, 2003; Paykel \& Cooper, 1992; Paykel, 1994). Although it appears evident that supportive interactions can be protective for health, the exact mechanisms are still unknown. It may be due to its self-esteem and positive feeling enhancing effects, which are thought to bolster the immune system, thus possibly reducing susceptibility to mental health problems (Cohen \& Syme, 1985; Jemmott \& Locke, 1984; Zimet, Dahlem, Zimet, \& Farley, 2010). It has also been postulated that social support may encourage health behaviours such as exercise and consumption of a healthy diet, as well as cessation of harmful habits such as smoking and alcohol consumption (Chouinard \& Robichaud-Ekstrand, 
2007; Emmons et al., 2007). Furthermore, the positive effects of social support are believed to influence HPA functioning and have moderating effects on brain regions supporting emotional responses (e.g., amygdala, prefrontal cortex; Eisenberger, Taylor, Gable, Hilmert, \& Lieberman, 2007; Ozbay et al., 2007; Rosal, King, Ma \& Reed, 2004; Uchino et al., 1996). Irrespective of the proposed processes involved, positive social interactions appear to buffer the effects stemming from stressor exposure.

\section{Unsupportive Social Interactions}

It is apparent that the absence of social support has a negative effect on stress reactivity and psychological well-being. Interestingly, unsupportive social interactions have still more damaging effects than does the lack of support (Song \& Ingram, 2002). Unsupport is not simply the absence of support, but instead comprises actions that directly undermine or minimize an individual's problems. These behaviours can include inappropriate or excessive help, criticism, withdrawal, dismissal, and closed body language (Ingram, Betz, Mindes, Schmitt \& Smith, 2001). Unsupportive social interactions can lead to increased psychological distress, low selfesteem, low interpersonal trust, external control beliefs, and various maladaptive attitudes (Lakey, Tardiff \& Drew, 1994). In essence, unsupportive behaviours are thought to have just as much of an influence on psychological well-being and mental health as a lack of supportive behaviours and possibly may even be more detrimental (Edwards, Hershberger, Russell \& Markert, 2001; Lincoln, 2000).

The effect of stressful life events on well-being and mental health can be exacerbated by the experience of unsupportive social interactions, thus unsupport may be predictive of psychological disturbances (Lakey et al., 1994). For example, negative social interactions were strongly related to disturbed psychological well-being in widowed women between the ages of 
60 and 89 (Rook, 1984). Likewise, women with fertility problems displayed impaired adjustment, increased depressive symptoms, and overall psychological distress after experiencing unsupportive responses from others (Mindes, Ingram, Kliewar \& James, 2003). Predictably, among rape victims, unsupportive social actions may have a strong impact on psychological adjustment as these actions directly altered recovery periods (Davis et al., 1991). Moreover, despite experiencing numerous stressors, unsupportive interactions among Somalian refugees was uniquely effective in promoting higher depressive and trauma symptomatology and unsupport also mediated the relationship between the experience of trauma and depressive symptoms (Jorden, Matheson \& Anisman, 2009). Also, the experience of negative social exchange was tied to depressive symptoms, psychological well-being, psychological distress, and physical health symptoms in undergraduate students (Edwards et al., 2001; Flett, Hewitt, Garshowitz \& Martin, 1997).

Unsupportive behaviour can have an especially detrimental effect on individuals diagnosed with an illness. For example, in breast cancer patients, there were significant relationships between concerns regarding failure to disclose and greater unsupportive social interactions as well as with low social support and low emotional well-being (Figueiredo, Fries \& Ingram, 2003). Similarly, after experiencing unsupportive social interactions, patients with HIV displayed increased mood disturbances (Song \& Ingram, 2002) and likewise, specific unsupportive responses (i.e., insensitivity, disconnecting, forced optimism and blaming) were predictive of depressive symptomatology (Ingram, Jones, Fass, Neidig, \& Song, 2010). Notably, the highest levels of depressive symptoms were found amongst patients who received unsupportive responses from a lover, spouse or close friend (Schrimshaw, 2003). Furthermore, quality of life ratings were significantly lower in individuals with severe mental illness (e.g. 
schizophrenia, depression) if they had experienced high levels of negative social interactions, particularly stigmatization (Yanos, Rosenfield \& Horwitz, 2001). It appears that unsupportive social actions may play a role in the association between stressful events and maladaptive responses thus negatively influencing resiliency to stressors. 


\section{Hypotheses}

The purpose of the present investigation is to examine whether there are relationships between social factors (i.e., supportive and unsupportive social interactions, social connectedness, and feelings of loneliness) and overall psychological well-being with mental health (i.e., depressive symptoms) and to assess whether these relationships are related to genetic factors (i.e., polymorphism in NPY). It is hypothesized that:

1. Negative relationships will exist between social support, social connectedness, and psychological well-being with depressive symptoms.

2. Positive relationships will exist between unsupportive social interactions and feelings of loneliness with depressive symptoms.

3. Genotype of the NPY SNP, rs16147, will moderate the relationships between these social factors with depressive symptomatology. 


\section{Methods}

\section{Participants}

Participants were first-year undergraduate students recruited online through a computer registry (SONA system) at Carleton University (Appendix A). The 253 participants recruited (M age $=19.15, \mathrm{SD}=2.174)$ were $70 \%$ female $(n=177, \mathrm{M}$ age $=18.97, \mathrm{SD}=1.985)$ and $30 \%$ male $(n=76, \mathrm{M}$ age $=19.59, \mathrm{SD}=2.526)$. This sample comprised 50.6\% $(n=128)$ White/EuroCaucasian, 17.4\% $(n=44)$ Black, 7.9\% $(n=20)$ Asian, 6.7\% $(n=17)$ South Asian, 6.3\% $(n=$ 16) Arab/West Asian, 2.8\% $(n=7)$ Latin American/Hispanic, 2.4\% $(n=6)$ South East Asian, $1.2 \%(n=3)$ Aboriginal, and 4.7\% $(n=12)$ Other (i.e. a mixed ethnicity or an ethnicity not listed).

\section{Procedure}

The study protocol was approved by the Psychology Research Ethics Board at Carleton University. Participant data were collected between fall 2014 and winter 2015. Upon receipt of informed consent (Appendix B), participants were given a set of questionnaires for completion and provided a saliva sample. Upon completion, participants were debriefed (Appendix C) and issued $1.25 \%$ experimental credit through the SONA system.

\section{Measures}

Background Information

Participants provided demographic details, medical history and information regarding current and past places of residence (Appendix D).

Depressive Symptoms

Presence and severity of typical depressive symptoms were assessed using the Beck 
Depression Inventory (BDI-21 item version; Beck, Ward, Mendelson, Mock, \& Erbaugh, 1961; Appendix E). The BDI is a widely used multiple-choice style inventory to measure the intensity of depressive symptoms. The BDI evaluates 21 depressive symptoms including: sadness, pessimism, past failure, self-dislike, self-criticism, suicidal ideation, crying, agitation, loss of interest, indecisiveness, worthlessness, loss of energy, changes in sleeping patterns, irritability, changes in appetite, difficulty concentrating, tiredness or fatigue, and loss of interest in sex. For each item, individuals select the statement that best described their emotional feelings scored from 0-3. Lower numbers (e.g., 0 and 1) indicated lower intensity of depressive symptoms while higher numbers (e.g., 2 and 3) were related to greater intensity. The overall intensity of depression is computed by summing the scores across the 21 items resulting in a score ranging from 0 to 63 . The score indicates the overall intensity of depression: 0-9 indicates minimal depression, 10-18 indicates mild-moderate depression, 19-29 indicates moderate-severe depression, and 30+ indicates severe depression. In the present study, the BDI displayed good reliability (Cronbach's $\alpha=.91)$.

As required by the Psychology Research Ethics Board at Carleton University, those individuals who had a total score of 30 or greater and those who scored 2a on item 9 of the BDI, which assesses suicidal ideation, were provided with an additional debriefing form which provides information about depression, and available resources (Appendix F). Those who scored $2 \mathrm{~b}$ or greater on item 9 of the BDI were administered the suicidal ideation protocol (Appendix G) and given additional debriefing.

\section{Psychological Resilience}

Psychological well-being defined as the combination of subjective positive states (e.g. happiness) and functioning with optimal effectiveness in individual and social life (e.g. life 
satisfaction), as well as health-related behaviours (Deci \& Ryan, 2008; Ryff, 1989) was measured using Ryff's Well-Being Scales (Clarke, Marshall, Ryff, \& Wheaton, 2001; Appendix H). This scale consists of six 14-item subscales designed to measure various dimensions of psychological well-being: self-acceptance (Cronbach's $\alpha=.92$ ), environmental mastery (Cronbach's $\alpha=.82$ ), positive relations with others (Cronbach's $\alpha=.89$ ), personal growth (Cronbach's $\alpha=.88$ ), purpose in life (Cronbach's $\alpha=.90$ ), and autonomy (Cronbach's $\alpha=.77$ ). Respondents select from a 6-point likert scale ranging from "Strongly Disagree" (one) to "Strongly Agree" (six). Scores are summed across the 14 items of each subscale resulting in a total between 14 and 84 . Psychological well-being scores have shown a negative association with depressive symptoms (Ryff, 1989; Ryff \& Keyes, 1995; Wells et al., 1989) and displayed positive correlations with resilience measures (Sagone \& De Caroli, 2014; Souri \& Hasanirad, 2011). Thus, it has been suggested that well-being may be useful as an adjunctive index of resilience (Galatzer-Levy, Burton, \& Bonanno, 2012; Ryff, 1989).

\section{Social Connectedness}

The psychological sense of belonging was measured using the Social Connectedness Scale - Revised (20-item SCS-R; Lee, Draper, \& Lee, 2001; Appendix I). Participants select responses based on a 6-point likert scale ranging from "Strongly Disagree" (one) to "Strongly Agree" (six) and a total score ranging from 20 to 120 is calculated by summing across all items with a higher score indicative of greater social connectedness. The SCS displayed good reliability (Cronbach's $\alpha=.95)$.

\section{Social Support}

Supportive social interactions were measured using the Social Provisions Scale (Cutrona \& Russell, 1987; Appendix J). This 24-item scale assesses the amount and quality of support 
participants perceive they have in current relationships to parents, peers, co-workers, community members, etc. The scale measures various types of supportive interactions including: attachment, social integration, reassurance of worth, reliable alliance, guidance, and opportunity for nurturance. Half of the items are based on the presence of specific supportive actions while the other half measures the absence of supportive actions. Answers are chosen from a 4-point likert scale ranging from "Strongly Disagree" (one) to "Strongly Agree" (four) with a total summed score ranging from 24 to 96 . Higher scores are indicative of a greater amount of perceived support. In the present study, the SPS displayed good reliability (Cronbach's $\alpha=.91$ ).

\section{Unsupport}

Unsupportive social interactions were measured using the Unsupportive Social Interactions Inventory (USII; Ingram, Betz, Mindes, Schmitt, \& Smith., 2001; Appendix K). This is a two part 24-item scale that assessed unsupportive or negative responses that the individual had received from friends and parents regarding stressful life situations. The inventory is comprised of four subscales: distancing (e.g., "did not seem to want to hear about it"), bumbling (e.g., "did not seem to know what to say"), minimizing (e.g., "said that I should look on the bright side"), and blaming (e.g., "made 'should' or 'shouldn't have' comments about my role in the event"). For each item, participants rated how frequent $(0=$ none; $4=$ a lot $)$ his or her friends and parents responded when he or she went to them for support. The USII is scored by calculating the mean rating across the items and displayed good reliability in the present study for both subscales (Cronbach's $\alpha=.91$ ).

\section{Loneliness}

Feelings of loneliness were measured using the UCLA Loneliness Scale Version 3 (20item UCLA L-Scale; Russell, 1996; Appendix L). The scale also measures feelings of social 
isolation. Reponses were selected ranging from "Never" (one) to "Always" (four) with a total summed across all 20 items. Higher scores indicated greater subjective feelings of loneliness. The questionnaire concludes by asking whether the participant feels lonely and if so, to specify how long he or she has felt this way ranging from days to months to years. The UCLA L-Scale displayed good reliability (Cronbach's $\alpha=.94)$.

\section{Genotype}

NORGEN Saliva DNA Isolation Kits were used to collect saliva samples $(\sim 2 \mathrm{ml})$ for subsequent isolation and purification of DNA from the preserved samples, which were then stored at $-80^{\circ} \mathrm{C}$. Steps for collection, preservation, and isolation were followed as outlined in the kits' instructions. All samples were diluted in ultrapure water to a concentration of $20 \mathrm{ng} / \mu \mathrm{l}$ and measured to $35 \mu 1$ prior to shipment. DNA samples were sent to the McGill University and Génome Québec Innovation Centre in Montreal, Quebec for SNP genotyping using Sequenom® ${ }^{\circledR}$ iPLEX ${ }^{\circledR}$ Gold Genotyping Technology.

Often, discernible differences in genotype distributions have been observed across ethnicities (Kim et al., 2010; Saphire-Bernstein et al., 2011). For example, the AA genotype of an OXTR gene SNP (rs53576) is the more common genotype among Asian ethnic groups, whereas the least common among Caucasians (Kim et al., 2011; Saphire-Berstein et al., 2011). Indeed, the genotype distribution of the NPY SNP, rs16147, varies across demographics (Sherry et al., 2001) and in the present study, these differences were also observed based on self-reported ethnicity, $\chi_{(16)}{ }^{2}=50.71, p<.001$ (Table 1). Therefore, a homogenous ethnic sample was used and although data were collected from non-Caucasian participants $(n=125)$, only Caucasian participants $(n=$ 128) were used for analyses involving genotype. The genotype distributions for Caucasian participants (Table 1) met Hardy-Weinberg Equilibrium expectations, $\chi^{2}=1.56, p=.49$. 
Genotypes for two participants were unable to be determined and thus, were excluded from all analyses conducted using genotype.

Table 1. NPY rs16147 gene polymorphism distributions by ethnicity $(n=248)$

\begin{tabular}{lccc}
\hline Ethnicity & AA & AG & GG \\
\hline White/Euro-Caucasian $(n=126)$ & 27 & 70 & 29 \\
Black $(n=43)$ & 22 & 16 & 5 \\
Asian $(n=20)$ & 1 & 9 & 10 \\
South Asian $(n=17)$ & 3 & 12 & 2 \\
Arab/West Asian $(n=15)$ & 4 & 7 & 4 \\
Latin American/Hispanic $(n=7)$ & 0 & 5 & 2 \\
South East Asian $(n=6)$ & 0 & 1 & 5 \\
Aboriginal $(n=3)$ & 0 & 1 & 2 \\
Other $(n=11)$ & 3 & 8 & 0 \\
\hline
\end{tabular}

\section{Statistical Analysis}

Statistical analyses were performed using SPSS Statistics software for Windows 18.0 (SPSS Science, Chicago, IL, USA). For all analyses, standardized scores were used and statistical significance was determined at $p<.05$ (two-tailed). Correlational analyses were performed to examine the relationships between depressive symptoms, psychological well-being, social support, unsupport, social connectedness, and feelings of loneliness. Differences between depression scores were assessed through analysis of variance (ANOVA) followed by Bonferonni corrected $t$-tests to compare between individual groups. Hierarchical linear regressions were used to determine whether or not the genotype for NPY moderated the relationship between psychological well-being, social support, unsupport, social connectedness, and loneliness with depression scores, and the significant moderations were followed up using a web utility for simple slopes (Preacher, Curran, \& Bauer, 2006). Moderations were analyzed using bootstrapping procedures and confidence intervals based on 5000 resamples (Preacher, Rucker, 
\& Hayes, 2007).

\section{Results}

\section{Bivariate Correlations}

Correlational analyses indicated that depressive symptoms were positively related to unsupport and loneliness as well as negatively related to social support and social connectedness, and to each subscale of psychological well-being (Table 3 and 4). Not surprisingly, overall psychological well-being was positively related to social support and social connectedness as well as negatively related to unsupport and loneliness (Table 3).

Table 2. Bivariate correlations depicting relations between depressive symptoms, overall psychological well-being, social support, social connectedness, unsupport, and loneliness. ( $n=$ 251)

\begin{tabular}{lcrrrrr}
\hline & 1 & 2 & 3 & 4 & 5 & 6 \\
\hline 1. Depressive Symptoms & & & & & & \\
2. Psychological Well-Being & $-.70^{* *}$ & & & & & \\
3. Social Support & $-.58^{* *}$ & $.70^{* *}$ & & & & \\
4. Social Connectedness & $-.63^{* *}$ & $.79^{* *}$ & $.74^{* *}$ & & & \\
5. Unsupport (friends) & $.44^{* *}$ & $-.41^{* *}$ & $-.34^{* *}$ & $-.35^{* *}$ & & \\
6. Unsupport (parents) & $.37^{* *}$ & $-.34^{* *}$ & $-.23^{* *}$ & $-.24^{* *}$ & $.57^{* *}$ & \\
7. Loneliness & $.67^{* *}$ & $-.78^{* *}$ & $-.76^{* *}$ & $-.89^{* *}$ & $.35^{* *}$ & $.24^{* *}$ \\
\hline
\end{tabular}


Table 3. Bivariate correlations depicting relations between depressive symptoms and the six subscales of psychological well-being. $(n=251)$

\begin{tabular}{|c|c|c|c|c|c|c|c|}
\hline & 1 & 2 & 3 & 4 & 5 & 6 & $\overline{7}$ \\
\hline \multicolumn{8}{|l|}{ 1. Depressive Symptoms } \\
\hline \multicolumn{8}{|l|}{ Psychological Well-Being Subscales } \\
\hline 2. Autonomy & $-.27^{* *}$ & & & & & & \\
\hline 3. Environmental Mastery & $-.61^{* *}$ & $.37^{* *}$ & & & & & \\
\hline 4. Personal Growth & $-.39^{* *}$ & $.41^{* *}$ & $.45^{* *}$ & & & & \\
\hline 5. Positive Relations with Others & $-.58^{* *}$ & $.29^{* *}$ & $.56^{* *}$ & $.53^{* *}$ & & & \\
\hline 6. Purpose in Life & $-.59^{* *}$ & $.34^{* *}$ & $.66^{* *}$ & $.59^{* *}$ & $.59^{* *}$ & & \\
\hline 7. Self-Acceptance & $-.74^{* *}$ & $.43^{* *}$ & $.73^{* *}$ & $.53^{* *}$ & $.66^{* *}$ & $.72^{* *}$ & \\
\hline
\end{tabular}

\section{Moderations}

It was hypothesized that the NPY genotype (rs16147) would be associated with depressive symptomatology. Since the mean depression scores among individuals with the AG and $\mathrm{GG}$ genotype were more similar $(\mathrm{M}=10.27 ; \mathrm{SE}=8.02$ and $\mathrm{M}=11.00 ; \mathrm{SE}=10.06$, respectively) than individuals with the AA genotype $(\mathrm{M}=15.19 ; \mathrm{SE}=13.27)$, all moderation analyses involving the NPY genotype compared the AA major allele to the pooled G carriers. After collapsing across the AG and GG carriers, differences were detected in depression scores, $\mathrm{F}_{(1,124)}=4.90, p=.03$.

It was also hypothesized that the NPY genotype would moderate the relationships between psychological well-being, social support, and unsupport with depressive symptoms. To examine the first relationship, Hayes' (2013) PROCESS macro for moderation was used wherein overall psychological well-being served as the predictor, NPY genotype as the moderator, and depression scores as the outcome variable. In this case, the NPY genotype moderated the 
relationship between overall psychological well-being and depressive symptoms, $b=.05(.02)$, $95 \% \mathrm{CI}[.01, .10], \mathrm{t}=2.20, \mathrm{p}=.03$. There was a negative relationship between overall psychological well-being and depression scores for AA $(b=-.16(.02), 95 \% \mathrm{CI}[-.20,-.13], \mathrm{t}=-$ 8.47, $\mathrm{p}<.001)$ and pooled G carriers $(b=-.11(.01), 95 \% \mathrm{CI}[-.14,-.09], \mathrm{t}=-9.29, \mathrm{p}<.001)$ and lower psychological well-being was accompanied by higher depression scores, which was greater among AA individuals (Figure 1). More specifically, NPY genotype moderated the relationship between environmental mastery $(b=.26(.13), 95 \% \mathrm{CI}[.01, .52], \mathrm{t}=2.02, \mathrm{p}=.04)$, positive relations with others $(b=.27(.10), 95 \% \mathrm{CI}[.06, .47], \mathrm{t}=2.57, \mathrm{p}=.01)$, and selfacceptance $(b=.23(.08), 95 \%$ CI $[.07, .39], \mathrm{t}=2.91, \mathrm{p}<.01)$ with depressive symptoms.

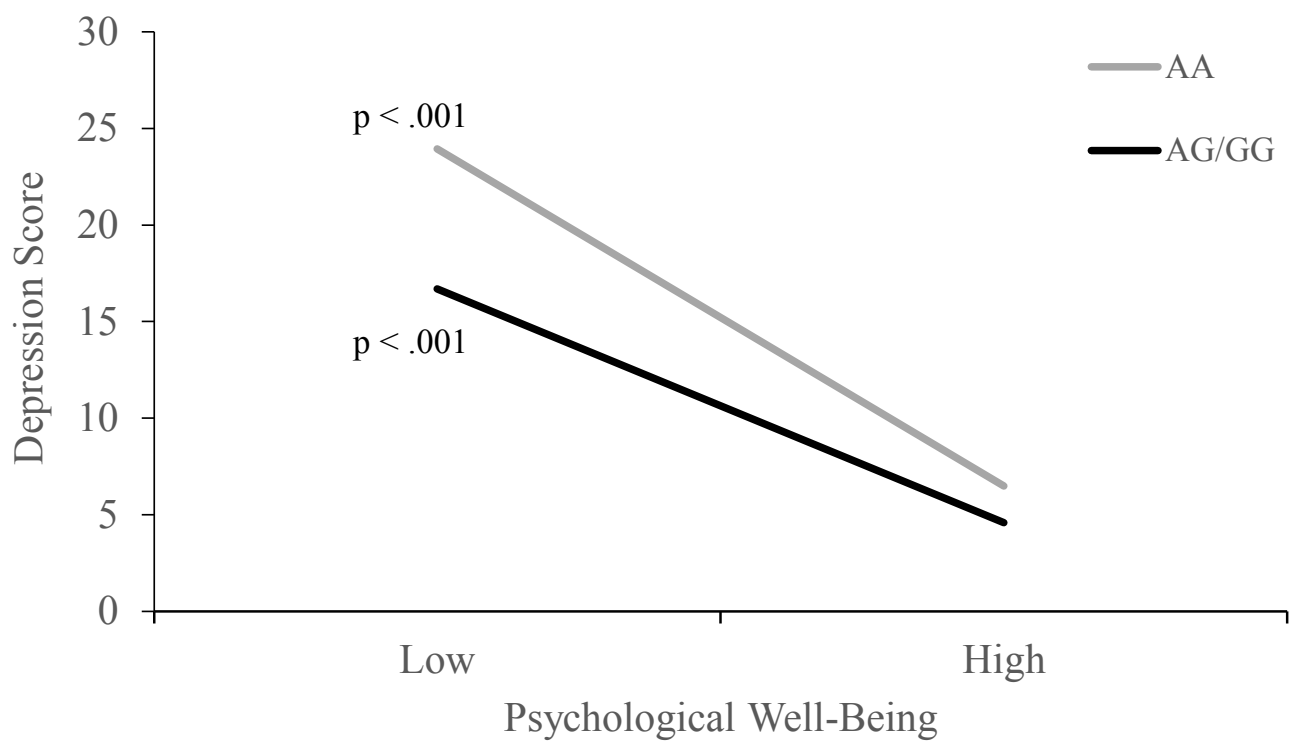

Figure 1. The relation between psychological well-being and depression scores as a function of the NPY genotype (AA vs. AG/GG).

A moderating role of NPY genotype was observed when social support served as the predictor, $b=7.08(3.06), 95 \% \mathrm{CI}[1.01,13.15], \mathrm{t}=2.31, \mathrm{p}=.02$, as high perceptions of social support were associated with lower depression scores for AA ( $b=-19.49(2.53), 95 \%$ CI [-24.50, $-14.48], \mathrm{t}=-7.70, \mathrm{p}<.001)$ and pooled $\mathrm{G}$ carriers $(b=-12.41(1.73), 95 \% \mathrm{CI}[-15.83,-8.99], \mathrm{t}=$ 
$-7.18, \mathrm{p}<.001)$ and low perception of social support was associated with greater depression scores, which were more pronounced among AA individuals (Figure 2).

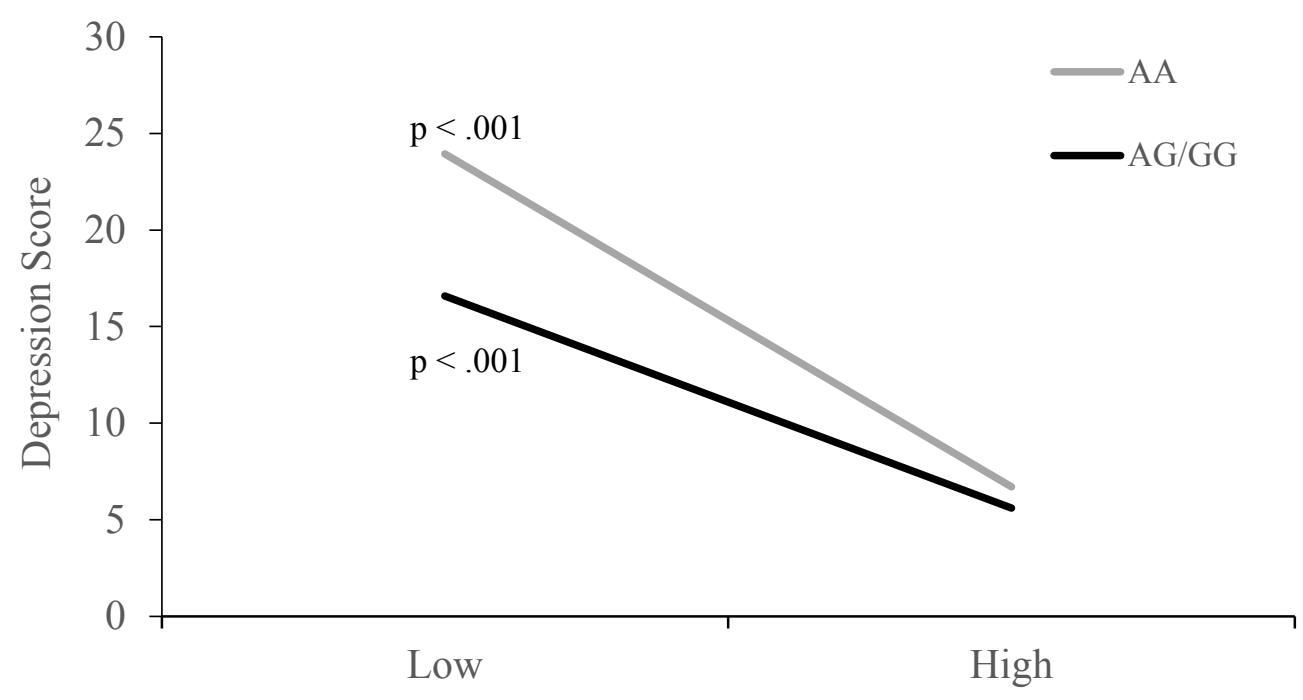

Social Support

Figure 2. The relation between social support and depression scores as a function of the NPY genotype (AA vs. AG/GG).

The relationship between unsupport and depression scores was also moderated by NPY genotype, but this effect was only significant when unsupportive interactions were received from friends, $b=-5.89(1.94), 95 \%$ CI $[-9.73,-2.05], \mathrm{t}=-3.04, \mathrm{p}<.01$, whereas this was not evident when unsupport came from parents, $b=-3.33(1.98), 95 \% \mathrm{CI}[-7.25, .59], \mathrm{t}=-1.68, \mathrm{p}=.09$. Furthermore, lower levels of unsupport were associated with lower depression scores for both AA $(b=11.77(1.63), 95 \%$ CI $[8.55,15.00], \mathrm{t}=7.22, \mathrm{p}<.001)$ and pooled $\mathrm{G}$ carriers $(b=5.87$ (1.05), 95\% CI $[3.80,7.96], \mathrm{t}=5.60, \mathrm{p}<.001)$ and high unsupport was accompanied by elevated depression scores, which were more prominent among AA individuals (Figure 3). 


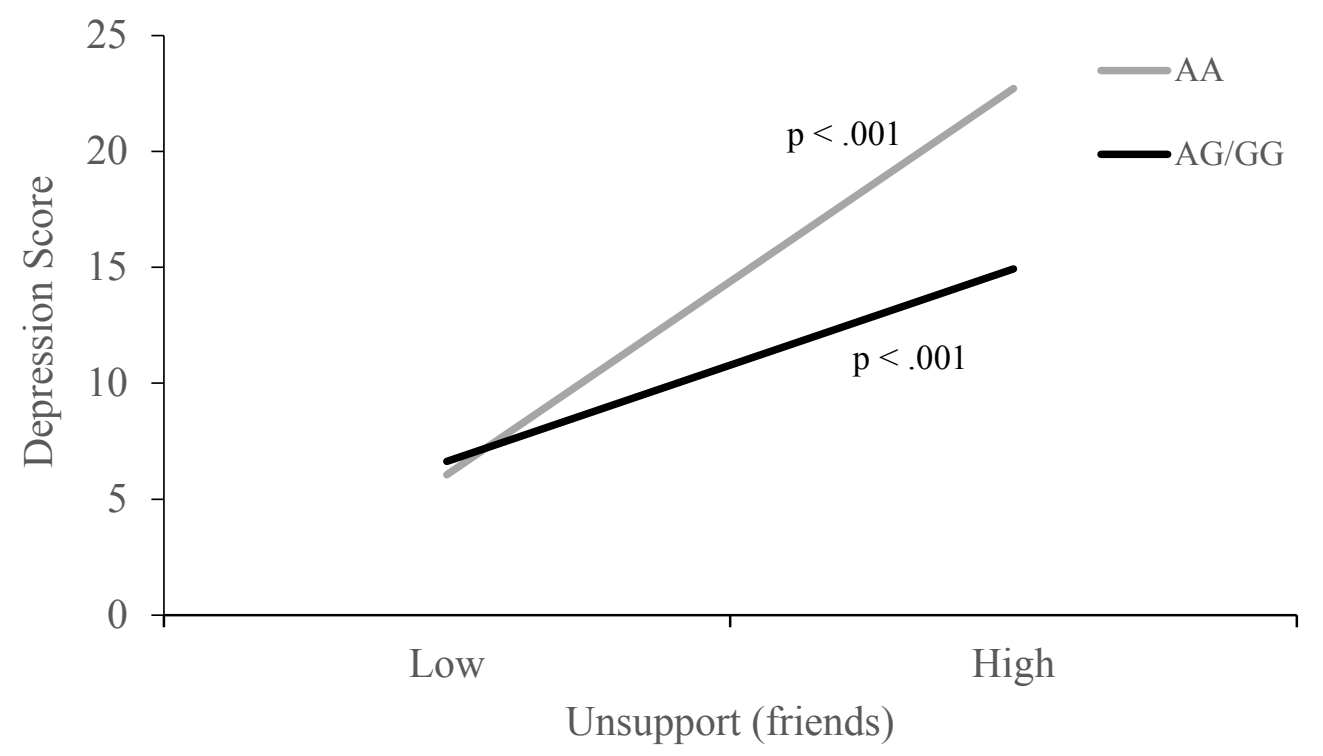

Figure 3. The relation between unsupport from friends and depression scores as a function of the NPY genotype (AA vs. AG/GG).

The NPY genotypes also moderated the relationships between both social connectedness $(b=.16(.06), 95 \% \mathrm{CI}[.03, .28], \mathrm{t}=-2.48, \mathrm{p}=.01)$ and loneliness $(b=-.23(.10), 95 \% \mathrm{CI}[-.42,-$ $.04], \mathrm{t}=-2.45, \mathrm{p}=.02$ ) with depression scores. There was a negative relationship between social connectedness and depression scores for AA $(b=-.45(.05), 95 \%$ CI $[-.56,-.35], \mathrm{t}=-8.53, \mathrm{p}<$ $.001)$ and pooled $\mathrm{G}$ carriers $(b=-.30(.03), 95 \% \mathrm{CI}[-.36,-.23], \mathrm{t}=-8.92, \mathrm{p}<.001)$ and lower connectedness was associated with higher depression scores, which was greater among AA individuals (Figure 4A). A positive relationship between loneliness and depression scores was observed for both AA $(b=.74(.08), 95 \%$ CI $[.58, .89], \mathrm{t}=9.26, \mathrm{p}<.001)$ and pooled $\mathrm{G}$ carriers $(b=.50(.05), 95 \% \mathrm{CI}[.40, .61], \mathrm{t}=9.74, \mathrm{p}<.001)$ and high loneliness scores were associated with greater depression scores and AA individuals displayed a more marked effect (Figure 4B). 

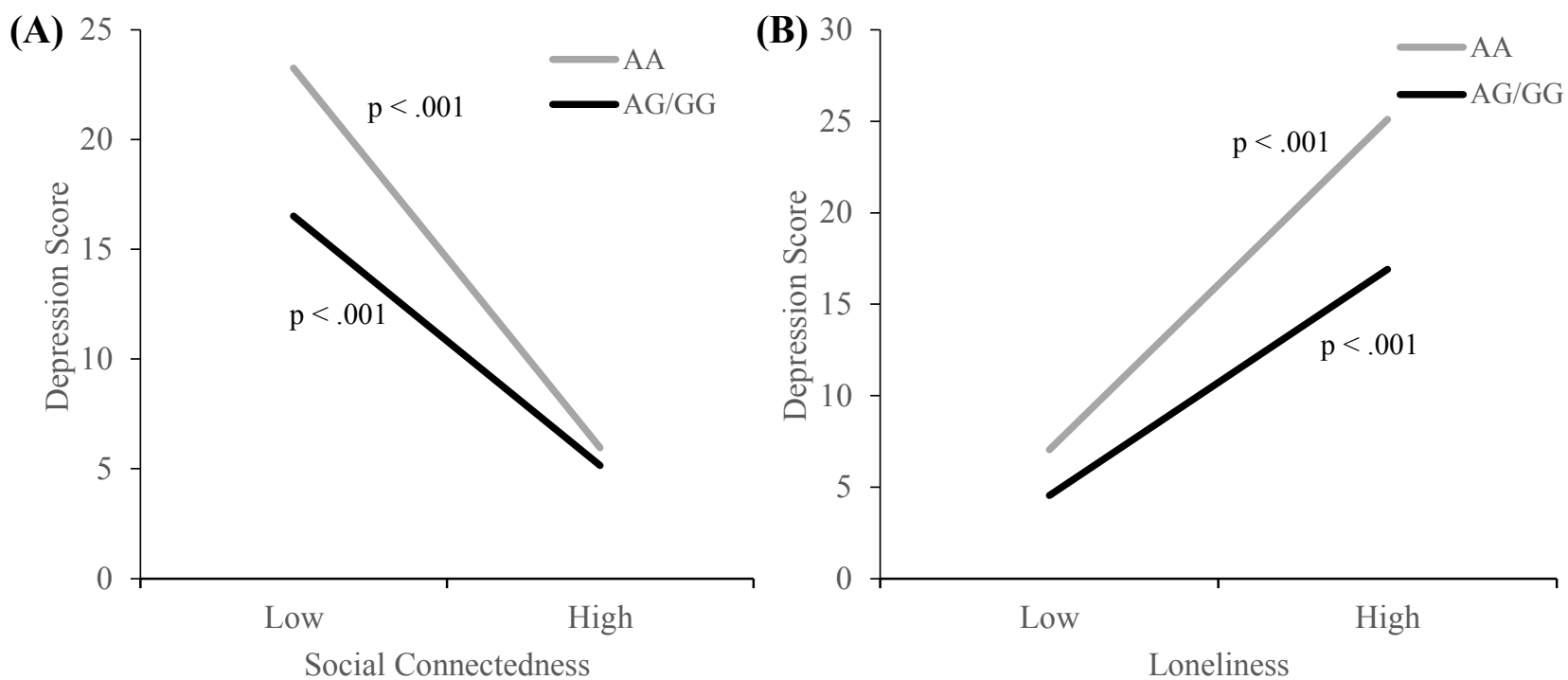

Figure 4. The relation between (A) social connectedness and (B) loneliness with depression scores as a function of the NPY rs16147 genotype (AA vs. AG/GG; $n=126$ ).

\section{Discussion}

The increase in responsibilities and the effects of moving away from established social networks may influence various aspects of mental health, including levels of distress, anxiety, and depressive symptoms in first-year university students (Adlaf et al., 2001; Mahmoud et al., 2012; Zarrett \& Eccles, 2006). Although, some appear to be adversely influenced by these novel stressors, others appear to be resilient, thus leading to the variability in the incidence of mental health problems among young adults. This variability may be accounted for by the differences in genotype related to NPY SNPs that possibly promote or act against psychological disorders (Heilig et al., 2004; Sjoholm et al., 2009). The variability may also be attributed to the interaction of these genotypes with psychosocial factors, such as the perception of supportive and unsupportive social interactions (Davis et al., 1991; Ozbay et al., 2007; Rook, 1987; Song \& Ingram, 2002).

The present study demonstrated that various facets of supportive social interactions (i.e., 
attachment, social integration, reassurance of worth, reliable alliance, guidance, and opportunity for nurturance) and social connectedness were negatively related to depressive symptomatology and positively related to psychological well-being. For example, high social support and social connectedness were associated with lower depression scores. This is consistent with previous research indicating that the perception and receipt of social support and a greater sense of social connectedness are accompanied by protection against susceptibility to negative health symptoms (i.e., depressive symptomatology) and enhanced overall psychological well-being, particularly in the context of stress-inducing experiences (Cairney et al., 2003; Christakis \& Fowler, 2009), in this case, the impact of stressors associated with university and sudden autonomy. Furthermore, the present study demonstrated that overall, each of the six dimensions of psychological wellbeing (i.e., self-acceptance, environmental mastery, positive relations with others, personal growth, purpose in life, and autonomy) were negatively associated with depression scores, which is in line with previous findings that had demonstrated such outcomes (Ryff, 1989; Ryff \& Keyes, 1995; Wells et al., 1989).

It was also found that unsupportive interactions from friends (i.e., distancing, bumbling, minimizing, and blaming) and feelings of loneliness were negatively related to psychological well-being and positively related to depressive symptoms. In other words, high unsupport from friends and feelings of loneliness were associated with greater depression scores. This corroborates earlier work indicating that unsupportive social interactions and feelings of loneliness are accompanied by poor mental health and psychological disturbances, such as increased depressive symptoms (Edwards et al., 2001; Jorden et al., 2009; Mindes et al., 2003) and these effects are more prominent during stressful experiences such as first year university as in this circumstance. 


\section{Moderating Effects of Genotype}

As hypothesized, the associations between the measured positive social behaviours with depression scores were related to the NPY genotype. Similarly, previous findings indicated that the NPY SNP (rs16147) modifies the risk of anxiety and depressive symptoms (Sommer et al., 2010) and influences treatment response in anxious depression (Domschke et al., 2009). In essence, the present findings indicated that NPY genotype itself is not predictive of depression, but rather that the interaction between social behaviours and certain NPY genotypes may be more associated with depressive symptoms. More specifically, the present findings showing that low perception of social support and low social connectedness were accompanied by higher depression scores and this effect appeared more prominent among individuals with the AA genotype. Similarly, positive relationships were found between both unsupport from friends and feelings of loneliness with the expression of depressive symptoms, and that these relations were more pronounced among individuals homozygous for the A allele. These findings contradict previous reports that implied that having the AA genotype conferred protective qualities in relation to stressors, whereas the $\mathrm{G}$ allele was associated with greater stress responses (Domschke et al., 2009; Zhou et al., 2008) and stress-related psychopathology (Sommer et al., 2010).

Earlier work had indicated this SNP was involved in transcriptional regulation and high promoter activity in vitro (Shah et al., 2009; Sommer et al., 2010; Zhou et al., 2008), although there have been inconsistencies concerning the influence of genotype on these processes. In this regard, individuals possessing the $\mathrm{G}$ allele displayed decreased messenger RNA expression and lower levels of plasma NPY (Zhou et al., 2008). In contrast, the A allele was accompanied by decreased reporter gene expression, which predicted lower NPY levels (Buckland et al., 2004; 
Itokawa et al., 2003). Additionally, the presence of the A allele was associated with a loss of an SP1 transcription factor binding site within the NPY rs16147 sequence, which predicted lower NPY expression, and may have thereby influenced vulnerability to psychological disturbances (Itokawa et al., 2003). Indeed, consistent with the current findings, it has been reported that the AA genotype was associated with decreased risk of generalized anxiety disorder (GAD) among individuals who experienced low stressor conditions, however, under high stressor conditions (i.e., hurricane exposure), AA individuals exhibited increased GAD risk (Amstadter et al., 2010). Thus, under greater stress-inducing circumstances, possessing the $\mathrm{G}$ allele may be protective from adverse mental health outcomes (i.e., depression). This was corroborated by the finding that plasma NPY levels were lower among G allele carriers under resting conditions (Zhou et al., 2008), but, when samples were taken under highly stressful (i.e., preoperative) conditions, plasma NPY levels were greater in individuals carrying the G allele (Shah et al., 2009).

Concordant with these studies, in the present investigation the relationships with the NPY SNP rs16147 varied among individuals in high- or low-stress inducing situations. Low psychological well-being, low social support, and low social connectedness, as well as high unsupport from friends and high feelings of loneliness, were associated with greater depression scores, but the increases in depressive symptoms were not as prominent among $\mathrm{G}$ carriers compared to AA individuals. Moreover, in the presence of high social support or low unsupport, possession of the $\mathrm{G}$ allele does not appear to influence depression scores. In essence, individuals may only benefit from greater NPY levels during high stressor conditions, while during low stressor conditions, NPY may have minimal or no effect. However, without having had measured plasma NPY levels from the current participant population, this cannot be known for certain. Also, by the inconsistent evidence, it is still unknown whether the A- or the G-allele controls 
expression of the NPY gene, thus controlling NPY levels. Regardless, it appears that the influence of NPY is dependent upon the environmental conditions. This is the first instance indicating that this NPY SNP may be related to the linkage between social behaviours (both supportive and unsupportive interactions) and depressive symptoms, potentially pointing to the buffering effects of NPY in relation to stress-inducing outcomes.

The present study demonstrated that while NPY appears to moderate the relationship between unsupport received from friends and depressive symptoms, this was not observed when unsupport is received from parents. Thus, it seems that the interaction between the NPY genotype and unsupport from friends may be associated with depression scores, but this same interaction was not apparent with respect to unsupport from parents. In effect, regardless of an individual's genotype, relationships with parents are important for the transition and adjustment to university (Wintre \& Yaffe, 2000; Wintre \& Sugar, 2000). However, as adolescents transition into adulthood, perceived supportive behaviours from parents decreases while it increases from friends (Helsen, Vollebergh, \& Meeus, 2000). The number and quality of friendships do have a prominent role in adjustment to new social environments, such as the first-year experience, and this is especially marked among students who have moved away from home (Buote et al., 2007). This does not suggest that peers are necessarily more important than parents, and indeed, the present findings suggest that the link between parental support and well-being is especially marked. However, this does not belie the possibility that peer support over time may become increasingly influential in young adulthoods.

\section{Limitations and Conclusions}

There are several limitations associated with the current findings. The sample size was modest, especially when considering the total number of individuals possessing the AA, GA, or 
GG genotype, and thus the conclusions drawn are highly provisional. Furthermore, it is not known whether analysis of resilience among first-year university students is relevant to resilience in other populations and in other stressor situations. This said, since this demographic appears to be at particular high risk for depressive and anxiety symptoms (Adlaf et al., 2001; Sax, 1997), the current findings may be useful in understanding links between stress-related resilience and the presence of mental health disturbances. Moreover, measures of social behaviours were collected using self-report questionnaires, and thus may have been subject to biases based on their affective state at the time of data collection. As a result, participants may have provided exaggerated responses concerning their perception of or lack of supportive or unsupportive interactions.

A particularly notable shortcoming of the present investigation concerned the time of year during which data were collected. The effect of a sudden increase in novel stressors may be particularly prominent during the first few months of the school year; however, in the present study data were collected throughout the entire school year. Thus, students recruited at the start of the year may have been experiencing more and greater stressors than those participants recruited later. Further to this, students recruited during the final months of the school year may have been those who were relatively resilient in the context of stressor experiences and thus remained enrolled in their respective program in comparison to students who had dropped out. Clearly, it would be useful to analyze the data in relation to various times of the school year, but the small number of participants enrolled precluded this being done.

Another caveat pertains to the specific SNP examined in the present investigation as it is thought to influence NPY levels as opposed to particular NPY receptors. However, it is uncertain whether a better strategy would be to examine potential genes for specific NPY receptors. In this 
regard, experiments in rodents revealed that NPY receptor Y1 (NPY1R) antagonists applied to the dorsal periaqueductal grey matter (Kask, Rago, \& Harro, 1996, 1998), the basolateral nucleus of the amygdala (Sajdyk, Vandergriff, \& Gehlert, 1999), and the dorsocaudal lateral septum (Kask, Nguyen, Pabst, \& von Horsten, 2001) decreased social interaction time and produced anxiogenic effects (Wahlestedt, Pich, Koob, Yee, \& Heilig, 1993). Conversely, NPY receptor Y2 (NPY2R) knockout mice displayed an anxiolytic-like phenotype during various behavioural tasks, indicating a NPY inhibiting role of Y2-type receptors (Redrobe, Dumont, Herzog, \& Quirion, 2003). Furthermore, activation of the NPY1R (Redrobe, Dumont, Fournier, \& Quirion, 2002) and deactivation of the NPY2R (Tschenett et al., 2003) appeared to produce antidepressant-like phenotypes in animal models of depression. In effect, it seems that the NPY1R and NPY2R may be involved in the regulation of anxiety and depressive-like behaviours and thus, may be more suitable candidates to study regarding genetic contributions to resilience.

In general, without a better understanding of the allele variant(s) responsible for transcriptional control of the NPY rs16147 promotor gene, it is difficult to determine whether the current findings help to explain whether there is a resilience-enhancing influence of NPY. Certainly measurement of plasma or salivary NPY levels would have been useful to better interpret the results. As mentioned earlier, the variability in the effects of NPY is thought to be dependent on environmental conditions. Notably, the contrasting effects of NPY expression by each allele variant may also be explained by differences due to brain region-dependent gene expression. For example, in humans, the A-variant appeared to control gene expression when NPY samples were taken from the cerebellum (Zhou et al., 2008), whereas the G-variant seemed to be responsible for gene expression when samples were taken from the anterior cingulate cortex (Sommer et al., 2010). Similarly, in rodent brains, gene mRNA expression varied as a 
function of genetic background as well as the brain region examined (Bjork et al., 2008; Hansson et al., 2006; Sommer et al., 2006). Thus, determining the exact relationship between gene variants and transcriptional control may be difficult to determine without further exploration of NPY gene expression across various brain regions. Furthermore, these inconsistencies also raise the question as whether rs16147 is the causal variant related to resilience, or whether it acts with other factors in this regard (Amstadter et al., 2010). Regardless of the specific allele variant involved, the current findings support the contention that the NPY SNP rs16147 interacts with psychosocial adversity in predicting depressive symptoms in young adults.

As mentioned, the transition from adolescence to adulthood can be perceived as exceptionally stressful (Adlaf et al., 2001; Sax, 1997). For these students, these stress-inducing circumstances can be alleviated through social support (Solberg \& Viliarreal, 1997; Verger et al., 2009) and high levels of social connectedness (Lee, Keough, \& Sexton, 2002; Yeh \& Inose, 2003), and can be exacerbated by unsupportive interactions (Edwards et al., 2001; Flett et al., 1997) and feelings of loneliness (Cacioppo et al., 2006; Yaacob et al., 2009). At the same time, there is considerable evidence linking genetic variation to individual differences in stress responses (Uher \& McGuffin, 2008). The current findings underscore the interaction between NPY and social behaviours and may explain individual responses to stress, and thus explain the variability in resiliency to depression. The first-year university experience is marked by various stressors and challenges which can be especially taxing on the mental health and well-being of young adults. Thus, it is important to better understand the relationships between genetic and psychosocial factors in order to recognize potential causes of depressive symptomatology sooner and to determine better methods of treatment. 


\section{References}

Abler, B., Erk, S., Herwig, U., \& Walter, H. (2007). Anticipation of aversive stimuli activates extended amygdala in unipolar depression. Journal of psychiatric research, 41(6), 511-522.

Adlaf, E. M., Gliksman, L., Demers, A., \& Newton-Taylor, B. (2001). The prevalence of elevated psychological distress among Canadian undergraduates: findings from the 1998 Canadian Campus Survey. Journal of American College Health, 50(2), 67-72.

Adrian, T. E., Allen, J. M., Bloom, S. R., Ghatei, M. A., Rossor, M. N., Roberts, G. W., Crow, T. J., Tatemoto, K., \& Polak, J. M. (1983). Neuropeptide Y distribution in human brain. Nature, 306, 584-586.

American Psychiatric Association. (2000). Diagnostic and Statistical Manual of Mental Disorders. (4th ed., text rev). Washington, DC: American Psychiatric Association. American Psychiatric Association. (2013). Diagnostic and Statistical Manual of Mental Disorders (5th ed.). Washington, DC: American Psychiatric Association.

Amstadter, A. B., Koenen, K. C., Ruggiero, K. J., Acierno, R., Galea, S., Kilpatrick, D. G., \& Gelernter, J. (2010). NPY moderates the relation between hurricane exposure and generalized anxiety disorder in an epidemiologic sample of hurricane-exposed adults. Depression and anxiety, 27(3), 270-275.

Anisman, H. (2015). Stress and Your Health: From Vulnerability to Resilience. John Wiley \& Sons.

Antonijevic, A., Murck, H., Bohlhalter, S., Frieboes, R., Holsboer, R., \& Steiger, A. (2000). Neuropeptide Y promotes sleep and inhibits ACTH and cortisol release in young men. Neuropharmacology, 39(8), 1474-1481.

Avison, W. R., \& Turner, R. J. (1988). Stressful life events and depressive symptoms: 
Disaggregating the effects of acute stressors and chronic strains. Journal of Health and Social Behavior, 253-264.

Beck, A.T., Ward, C.H., Mendelson, M., Mock, J., \& Erbaugh, J. (1961). An inventory of measuring depression. Archives of Gerenal Psychiatry, 4, 561-571.

Beekman, A. T. F., Deeg, D. J. H., van Tilburg, T., Smit, J. H., Hooijer, C., \& van Tilburg, W. (1995). Major and minor depression in later life: a study of prevalence and risk factors. Journal of Affective Disorders, 36(1-2), 65-75.

Björk, K., Rimondini, R., Hansson, A. C., Terasmaa, A., Hyytiä, P., Heilig, M., \& Sommer, W. H. (2008). Modulation of voluntary ethanol consumption by beta-arrestin 2. The FASEB Journal, 22(7), 2552-2560.

Blackburn-Munro, G., \& Blackburn-Munro, R. E. (2001). Chronic pain, chronic stress and depression: coincidence or consequence. Journal of Neuroendocrinology, 13(12), 10091023.

Booth, B. M., Russell, D. W., Soucek, S., \& Laughlin, P. R. (1992). Social support and outcome of alcoholism treatment: An exploratory analysis. The American journal of drug and alcohol abuse, 18(1), 87-101.

Bremner, J. D., Narayan, M., Anderson, E. R., Staib, L. H., Miller, H. L., \& Charney, D. S. (2000). Hippocampal volume reduction in major depression. Am J Psychiatry, 157(1), 115118.

Breslau, N., \& Davis, G. C. (1986). Chronic stress and major depression.Archives of General Psychiatry, 43(4), 309-314.

Brown, E. S., Varghese, F. P., \& McEwen, B. S. (2004). Association of depression with medical illness: does cortisol play a role?. Biological psychiatry, 55(1), 1-9. 
Brown, G. W., \& Harris, T. (1978). Social origins of depression: a reply.Psychological Medicine, 8(4), 577-588.

Brown, G. W., \& Harris, T. O. (Eds.). (1989). Life events and illness. Guilford Press.

Bruce, M. L., \& Hoff, R. A. (1994). Social and physical health risk factors for first-onset major depressive disorder in a community sample. Social psychiatry and psychiatric epidemiology, 29(4), 165-171.

Buckland, P. R., Hoogendoorn, B., Guy, C. A., Coleman, S. L., Smith, S. K., Buxbaum, J. D., ... \& O'Donovan, M. C. (2004). A high proportion of polymorphisms in the promoters of brain expressed genes influences transcriptional activity. Biochimica et Biophysica Acta (BBA)-Molecular Basis of Disease, 1690(3), 238-249.

Buote, V. M., Pancer, S. M., Pratt, M. W., Adams, G., Birnie-Lefcovitch, S., Polivy, J., \& Wintre, M. G. (2007). The importance of friends friendship and adjustment among 1st-year university students. Journal of Adolescent Research, 22(6), 665-689.

Cabib, S., \& Puglisi-Allegra, S. (1996). Stress, depression and the mesolimbic dopamine system. Psychopharmacology, 128(4), 331-342.

Cacioppo, J. T., Hughes, M. E., Waite, L. J., Hawkley, L. C., \& Thisted, R. A. (2006). Loneliness as a specific risk factor for depressive symptoms: cross-sectional and longitudinal analyses. Psychology and Aging, 21(1), 140.

Cairney, J., Boyle, M., Offord, D. R., \& Racine, Y. (2003). Stress, social support and depression in single and married mothers. Social psychiatry and psychiatric epidemiology, 38(8), 442449.

Canadian Mental Health Association. (2015). Fast Facts about Mental Illness. Ottawa, Canada: Canadian Mental Health Association. 
Catania, J. A., Turner, H. A., Choi, K. H., \& Coates, T. J. (1992). Coping with death anxiety: help-seeking and social support among gay men with various HIV diagnoses. Aids, 6(9), 999-1006.

Charney, D. S. (2004). Psychobiological mechanism of resilience and vulnerability: implications for successful adaptation to extreme stress. Am J Psychiatry, 161, 195- 216.

Checkley, S. (1996). The neuroendrocrinology of depression and stress. British Medical Bulletin, $52(3), 597-617$.

Chen, F. S., Kumsta, R., von Dawans, B., Monakhov, M., Ebstein, R. P., \& Heinrichs, M. (2011). Common oxytocin receptor gene (OXTR) polymorphism and social support interact to reduce stress in humans. Proceedings of the National Academy of Sciences, 108(50), 19937-19942.

Chouinard, M. C., \& Robichaud-Ekstrand, S. (2007). Predictive value of the transtheoretical model to smoking cessation in hospitalized patients with cardiovascular disease. European Journal of Cardiovascular Prevention \& Rehabilitation, 14(1), 51-58.

Christakis, N. A., \& Fowler, J. H. (2009). Connected: The Surprising Power of our Social Networks and How they Shape our Lives. New York, NY: Back Bay Books.

Clarke, P.J., Marshall, V.W., Ryff, C.D., \& Wheaton, B. (2001). Measuring Psychological WellBeing in the Canadian Study of Health and Aging. International Psychogeriatrics, 13, 7990.

Cobb, S. (1976). Social support as a moderator of life stress. Psychosomatic medicine, 38(5), 300-314.

Cohen, S., \& Syme, S. L. (1985). Issues in the study and application of social support. Social support and health, 3, 3-22. 
Cohen, S., \& Wills, T. A. (1985). Stress, social support, and the buffering hypothesis. Psychological bulletin, 98(2), 310.

Cuijpers, P., de Graaf, R., \& van Dorsselaer, S. (2004). Minor depression: risk profiles, functional disability, health care use and risk of developing major depression. Journal of affective disorders, 79(1), 71-79.

Cutrona, C. E., \& Russell, D. W. (1987). The provisions of social relationships and adaptation to stress. Advances in personal relationships, 1(1), 37-67.

Davis, R. C., Brickman, E., \& Baker, T. (1991). Supportive and unsupportive responses of others to rape victims: Effects of concurrent victim adjustment. American Journal of Community Psychology, 19(3), 443-451.

de Araujo, G., Dudley, D. L., \& Van Arsdel, P. P. (1972). Psychosocial assets and severity of chronic asthma. Journal of Allergy and Clinical Immunology,50(5), 257-263.

de Araujo, G., Van Arsdel, P. P., Holmes, T. H., \& Dudley, D. L. (1973). Life change, coping ability and chronic intrinsic asthma. Journal of Psychosomatic Research, 17(5), 359-363.

de Bono, M., \& Bargmann, C. I. (1998). Natural variation in a neuropeptide Y receptor homolog modifies social behavior and food response in C. elegans.Cell, 94(5), 679-689.

de Bono, M., Tobin, D. M., Davis, M. W., Avery, L., \& Bargmann, C. I. (2002). Social feeding in Caenorhabditis elegans is induced by neurons that detect aversive stimuli. Nature, 419(6910), 899-903.

Deci, E. L., \& Ryan, R. M. (2008). Facilitating optimal motivation and psychological well-being across life's domains. Canadian Psychology/Psychologie canadienne, 49(1), 14.

Del Rey, A., Chrousos, G., \& Besedovsky, H. (2008). The hypothalamus-pituitary-adrenal $\operatorname{axis}$ (Vol. 7). Elsevier. 
DiMatteo, M. R. (2004). Social support and patient adherence to medical treatment: a metaanalysis. Health psychology, 23(2), 207.

Dohrenwend, B. P., Levav, I., Shrout, P. E., Schwartz, S., Naveh, G., Link, B. G., ... \& Stueve, A. (1992). Socioeconomic status and psychiatric disorders: the causation-selection issue. Science(Washington), 255(5047), 946-952.

Domschke, K., Dannlowski, U., Hohoff, C., Ohrmann, P., Bauer, J., Kugel, H., Zwanzger, P., Heindel, W., Deckert, J., Arolt, V., Suslow, T., Baune, B.T. (2010). Neuropeptide Y (NPY) gene: Impact on emotional processing and treatment response in anxious depression. European Neuropsychopharmacology, 20(5), 301-309.

Dyrbye, L. N., Thomas, M. R., \& Shanafelt, T. D. (2006). Systematic review of depression, anxiety, and other indicators of psychological distress among US and Canadian medical students. Academic Medicine, 81(4), 354-373.

Edwards, K. J., Hershberger, P. J., Russell, R. K., \& Markert, R. J. (2001). Stress, negative social exchange, and health symptoms in university students.Journal of American College Health, 50(2), 75-79.

Eisenberger, N. I., Taylor, S. E., Gable, S. L., Hilmert, C. J., \& Lieberman, M. D. (2007). Neural pathways link social support to attenuated neuroendocrine stress responses. Neuroimage, 35(4), 1601-1612.

Emmons, K. M., Barbeau, E. M., Gutheil, C., Stryker, J. E., \& Stoddard, A. M. (2007). Social influences, social context, and health behaviors among working-class, multi-ethnic adults. Health Education \& Behavior, 34(2), 315-334.

Feder, A., Nestler, E. J., \& Charney, D. S. (2009). Psychobiology and molecular genetics of resilience. Nature Reviews Neuroscience, 10(6), 446-457. 
Ferrari, A. J., Charlson, F. J., Norman, R. E., Patten, S. B., Freedman, G., Murray, C. J., ... \& Whiteford, H. A. (2013). Burden of depressive disorders by country, sex, age, and year: findings from the global burden of disease study 2010. PLOS Medicine, 10(11), 1-12.

Figueiredo, M. I., Fries, E., \& Ingram, K. M. (2004). The role of disclosure patterns and unsupportive social interactions in the well-being of breast cancer patients. PsychoOncology, 13(2), 96-105.

Flett, G. L., Hewitt, P. L., Garshowitz, M., \& Martin, T. R. (1997). Personality, negative social interactions, and depressive symptoms. Canadian Journal of Behavioural Science/Revue canadienne des sciences du comportement, $29(1), 28$.

Frodl, T., Meisenzahl, E., Zetzsche, T., Bottlender, R., Born, C., Groll, C., ... \& Möller, H. J. (2002). Enlargement of the amygdala in patients with a first episode of major depression. Biological psychiatry, 51(9), 708-714.

Galatzer-Levy, I. R., Burton, C. L., \& Bonanno, G. A. (2012). Coping flexibility, potentially traumatic life events, and resilience: A prospective study of college student adjustment. Journal of Social and Clinical Psychology, 31(6), 542-567.

Garay-Sevilla, M. E., Nava, L. E., Malacara, J. M., Huerta, R., de León, J. D., Mena, A., \& Fajardo, M. E. (1995). Adherence to treatment and social support in patients with noninsulin dependent diabetes mellitus. Journal of Diabetes and its Complications, 9(2), 8186.

Gonzalez, J. S., Penedo, F. J., Antoni, M. H., Durán, R. E., McPherson-Baker, S., Ironson, G., ... \& Schneiderman, N. (2004). Social support, positive states of mind, and HIV treatment adherence in men and women living with HIV/AIDS.Health Psychology, 23(4), 413. Goodyer, I. M., Herbert, J., \& Altham, P. M. E. (1998). Adrenal steroid secretion and major 
depression in 8-to 16-year-olds, III. Influence of cortisol/DHEA ratio at presentation on subsequent rates of disappointing life events and persistent major depression. Psychological Medicine, 28(2), 265-273.

Hammen, C. (1991). Generation of stress in the course of unipolar depression.Journal of abnormal psychology, 100(4), 555.

Hammen, C. (1992). Life events and depression: The plot thickens. American Journal of Community Psychology, 20(2), 179-193.

Hammen, C. (2005). Stress and depression. Annu. Rev. Clin. Psychol., 1, 293-319.

Hammen, C., Shih, J. H., \& Brennan, P. A. (2004). Intergenerational transmission of depression: test of an interpersonal stress model in a community sample. Journal of consulting and clinical psychology, 72(3), 511.

Hansson, A. C., Cippitelli, A., Sommer, W. H., Fedeli, A., Björk, K., Soverchia, L., ... \& Ciccocioppo, R. (2006). Variation at the rat Crhrl locus and sensitivity to relapse into alcohol seeking induced by environmental stress. Proceedings of the National Academy of Sciences, 103(41), 15236-15241.

Hashimoto, H., Onishi, H., Koide, S., Kai, T., \& Yamagami, S. (1996). Plasma neuropeptide Y in patients with major depressive disorder. Neurosci Lett, 216, 57-60.

Haslam, S. A. (2004). Psychology in organizations: The social identity approach (2nd ed.). London: Sage.

Haslam, S. A., Jetten, J., O’Brien, A., \& Jacobs, E. (2004). Social identity, social influence, and reactions to potentially stressful tasks: Support for the self-categorization model of stress. Stress and Health, 20, 3-9.

Haslam, S. A., O’Brien, A., Jetten, J., Vormedal, K., \& Penna, S. (2005). Taking the strain: social 
identity, social support, and the experience of stress. British Journal of Social Psychology, 44, 355-370.

Hasler, G., Drevets, W. C., Manji, H. K., \& Charney, D. S. (2004). Discovering endophenotypes for major depression. Neuropsychopharmacology, 29(10), 1765-1781.

Hausser, J. A., Kattenstroth, M., van Dick, R., \& Mojzisch, A. (2012). "We” are not stressed: Social identity in groups buffers neuroendocrine stress reactions. Journal of Experimental Social Psychology, 48, 973-977.

Health Canada. (2009). Depression. Retrieved from http://www.hc-sc.gc.ca/hlvs/alt_formats/pacrb-dgapcr/pdf/iyh-vsv/diseases-maladies/depression-eng.pdf

Heilig, M., \& Widerlöv, E. (1990). Neuropeptide Y: an overview of central distribution, functional aspects, and possible involvement in neuropsychiatric illnesses. Acta Psychiatrica Scandinavica, 82(2), 95-114.

Heilig, M., Zachrisson, O., Thorsell, A., Ehnvall, A., Mottagui-Tabar, S., Sjögren, M., Asberg, M., Ekman, R., Wahlestedt, C., \& Ågren, H. (2004). Decreased cerebrospinal fluid neuropeptide Y (NPY) in patients with treatment refractory unipolar major depression: preliminary evidence for association with preproNPY gene polymorphism. Journal of Psychiatric Research, 38(2), 113-121.

Helsen, M., Vollebergh, W., \& Meeus, W. (2000). Social support from parents and friends and emotional problems in adolescence. Journal of Youth and Adolescence, 29(3), 319-335.

Herbert, T. B., \& Cohen, S. (1993). Stress and immunity in humans: A meta-analytic review. Psychosomatic Medicine, 364-379.

Holahan, C. J., Moos, R. H., Holahan, C. K., \& Brennan, P. L. (1995). Social support, coping, and depressive symptoms in a late-middle-aged sample of patients reporting cardiac 
illness. Health Psychology, 14(2), 152.

Hou, C., Jia, F., Liu, Y., \& Li, L. (2006). CSF serotonin, 5-hydroxyindolacetic acid and neuropeptide Y levels in severe major depressive disorder. Brain research, 1095(1), 154158.

Hultman, C. M., Wieselgren, I. M., \& Öhman, A. (1997). Relationships between social support, social coping and life events in the relapse of schizophrenic patients. Scandinavian Journal of Psychology, 38(1), 3-13.

Ingram, K. M., Jones, D. A., Fass, R. J., Neidig, J. L., \& Song, Y. S. (1999). Social support and unsupportive social interactions: Their association with depression among people living with HIV. AIDS care, 11(3), 313-329.

Ingram, K.M., Betz, N.E., Mindes, E.J., Schmitt, M.M. \& Smith, N.G. (2001). Unsupportive social interactions from others concerning a stressful life event: Development of the unsupportive social interactions inventory. Journal of Social and Clinical Psychology, 20, 173-207.

Itokawa, M., Arai, M., Kato, S., Ogata, Y., Furukawa, A., Haga, S., ... \& Yoshikawa, T. (2003). Association between a novel polymorphism in the promoter region of the neuropeptide $\mathrm{Y}$ gene and schizophrenia in humans.Neuroscience letters, 347(3), 202-204.

Jackson, S. E., Schwab, R. L., \& Schuler, R. S. (1986). Toward an understanding of the burnout phenomenon. Journal of applied psychology,71(4), 630.

Jemmott, J. B., \& Locke, S. E. (1984). Psychosocial factors, immunologic mediation, and human susceptibility to infectious diseases: How much do we know?. Psychological Bulletin, 95(1), 78 .

Jorden, S., Matheson, K., \& Anisman, H. (2009). Supportive and unsupportive social interactions 
in relation to cultural adaptation and psychological distress among Somali refugees exposed to collective or personal traumas. Journal of Cross-Cultural Psychology, 40(5), 853-874.

Judd, L. L., Akiskal, H. S., \& Paulus, M. P. (1997). The role and clinical significance of subsyndromal depressive symptoms (SSD) in unipolar major depressive disorder. Journal of affective disorders, 45(1), 5-18.

Kallio, J., Pesonen, U., Jaakkola, U., Karvonen, M. K., Helenius, H., \& Koulu, M. (2003). Changes in diurnal sympathoadrenal balance and pituitary hormone secretion in subjects with Leu7Pro polymorphism in the prepro-neuropeptide Y. The Journal of Clinical Endocrinology \& Metabolism, 88(7), 3278-3283.

Kamarck, T. W., Annunziato, B., \& Amateau, L. M. (1995). Affiliation moderates the effects of social threat on stress-related cardiovascular responses: Boundary conditions for a laboratory model of social support. Psychosomatic Medicine, 57(2), 183-194..

Karlamangla, A. S., Singer, B. H., McEwen, B. S., Rowe, J. W., \& Seeman, T. E. (2002). Allostatic load as a predictor of functional decline. MacArthur studies of successful aging. Journal of Clinical Epidemiology, 55, 696-710

Kask, A., Nguyen, H. P., Pabst, R., \& Von Hörsten, S. (2001). Neuropeptide YY 1 receptormediated anxiolysis in the dorsocaudal lateral septum: functional antagonism of corticotropin-releasing hormone-induced anxiety. Neuroscience,104(3), 799-806.

Kask, A., Rägo, L., \& Harro, J. (1996). Anxiogenic-like effect of the neuropeptide YY 1 receptor antagonist BIBP3226: antagonism with diazepam.European journal of pharmacology, 317(2), R3-R4.

Kask, A., Rägo, L., \& Harro, J. (1998). NPY Y1 receptors in the dorsal periaqueductal gray 
matter regulate anxiety in the social interaction test.Neuroreport, $9(12), 2713-2716$.

Keith, C. R. (2001). Adolescent suicide: perspectives on a clinical quandary. JAMA, 286(24), 3126-3127.

Kendler, K. S., Karkowski, L. M., \& Prescott, C. A. (1999). Causal relationship between stressful life events and the onset of major depression. American Journal of Psychiatry, 156(6), $837-841$.

Kendler, K. S., Kessler, R. C., Walters, E. E., MacLean, C., Neale, M. C., Heath, A. C., \& Eaves, L. J. (2010). Stressful life events, genetic liability, and onset of an episode of major depression in women. Focus, 8(3), 459-470.

Kessler, R. C., \& Walters, E. E. (1998). Epidemiology of DSM-III-R major depression and minor depression among adolescents and young adults in the national comorbidity survey. Depression and anxiety, 7(1), 3-14.

Kessler, R. C., Zhao, S., Blazer, D. G., \& Swartz, M. (1997). Prevalence, correlates, and course of minor depression and major depression in the National Comorbidity Survey. Journal of affective disorders, 45(1), 19-30.

Kim, H. S., Sherman, D. K., Sasaki, J. Y., Xu, J., Chu, T. Q., Ryu, C., ... \& Taylor, S. E. (2010). Culture, distress, and oxytocin receptor polymorphism (OXTR) interact to influence emotional support seeking. Proceedings of the National Academy of Sciences, 107(36), $15717-15721$.

Kupfer, D. J., Frank, E., \& Wamhoff, J. (1996). 17 Mood disorders: update on prevention of recurrence. Interpersonal factors in the origin and course of affective disorders, 289-301.

Laakso, H., \& Paunonen-Ilmonen, M. (2002). Mothers' experience of social support following the death of a child. Journal of clinical nursing, 11(2), 176-185. 
Lakey, B., Tardiff, T. A., \& Drew, J. B. (1994). Negative social interactions: Assessment and relations to social support, cognition, and psychological distress. Journal of Social and Clinical Psychology, 13(1), 42-62.

Lange, C., \& Irle, E. (2004). Enlarged amygdala volume and reduced hippocampal volume in young women with major depression. Psychological medicine, 34(06), 1059-1064.

Lee, R. M., Draper, M., Lee, S. (2001). Social connectedness, dysfunctional interpersonal behaviors, and psychological distress: Testing a mediator model. Journal of Counselling Psychology, 48, 310-318.

Lee, R. M., Keough, K. A., \& Sexton, J. D. (2002). Social connectedness, social appraisal, and perceived stress in college women and men. Journal of Counseling \& Development, 80(3), $355-361$.

Lenz, B. (2001). The transition from adolescence to young adulthood: a theoretical perspective. The Journal of School Nursing, 17(6), 300-306.

Lepore, S. J., Allen, K. A. M., \& Evans, G. W. (1993). Social support lowers cardiovascular reactivity to an acute stressor. Psychosomatic Medicine, 55, 518-524.

Lesch, K. P. (2004). Gene-environment interaction and the genetics of depression. Journal of Psychiatry and Neuroscience, 29(3), 174.

Levine, R. M., Cassidy, C., Brazier, G., \& Reicher, S. D. (2002). Self-categorization and bystander non-intervention: Two experimental studies. Journal of Applied Social Psychology, 32, 1452-1463.

Lin, N., Ensel, W. M., Simeone, R. S., \& Kuo, W. (1979). Social support, stressful life events, and illness: A model and an empirical test. Journal of Health and Social Behavior, 108119. 
Lincoln, K. D. (2000). Social support, negative social interactions, and psychological wellbeing. Social Service Review, 74(2), 231-252.

Mahmoud, J. S. R., Staten, R. T., Hall, L. A., \& Lennie, T. A. (2012). The relationship among young adult college students' depression, anxiety, stress, demographics, life satisfaction, and coping styles. Issues in mental health nursing, 33(3), 149-156.

Mann, J. J. (2003). Neurobiology of suicidal behaviour. Nature Reviews Neuroscience, 4(10), 819-828.

Mann, J. J., Oquendo, M., Underwood, M. D., \& Arango, V. (1999). The neurobiology of suicide risk: a review for the clinician. Journal of Clinical Psychiatry, 60, 7-11.

Maren, S. (2001). Neurobiology of Pavlovian fear conditioning. Annual review of neuroscience, 24(1), 897-931.

Mazure, C. M. (1998). Life stressors as risk factors in depression. Clinical Psychology: Science and Practice, 5(3), 291-313.

McEwen, B. S. (2000). Allostasis and allostatic load: implications for neuropsychopharmacology. Neuropsychopharmacology, 22(2), 108-124.

McEwen, B. S. (2004). Protection and damage from acute and chronic stress: allostasis and allostatic overload and relevance to the pathophysiology of psychiatric disorders. Annals of the New York Academy of Sciences, 1032(1), 1-7.

McEwen, B. S. (2006). Protective and damaging effects of stress mediators: central role of the brain. Dialogues in clinical neuroscience, 8(4), 367.

McGonagle, K. A., \& Kessler, R. C. (1990). Chronic stress, acute stress, and depressive symptoms. American journal of community psychology, 18(5), 681-706.

Mindes, E. J., Ingram, K. M., Kliewer, W., \& James, C. A. (2003). Longitudinal analyses of the 
relationship between unsupportive social interactions and psychological adjustment among women with fertility problems. Social science \& medicine, 56(10), 2165-2180.

Morgan, C. A., Rasmusson, A. M., Wang, S., Hoyt, G., Hauger, R. L., \& Hazlett, G. (2002).

Neuropeptide-Y, cortisol, and subjective distress in humans exposed to acute stress: replication and extension of previous report. Biological psychiatry, 52(2), 136-142.

Morgan, C. A., Southwick, S., Hazlett, G., Rasmusson, A., Hoyt, G., \& Charney, D. (2004). Relationships among plasma dehydroepiandrosterone sulfate and cortisol levels, symptoms of dissociation and objective performance in humans exposed to acute stress. Archives of General Psychiatry, 61, 819-825.

Morgan, C. A., Wang, S., Southwick, S. M., Rasmusson, A., Hazlett, G., Hauger, R. L., \& Charney, D. S. (2000). Plasma neuropeptide-Y concentrations in humans exposed to military survival training. Biological psychiatry, 47(10), 902-909.

Murphy, J. M., Olivier, D. C., Monson, R. R., Sobol, A. M., Federman, E. B., \& Leighton, A. H. (1991). Depression and anxiety in relation to social status: a prospective epidemiologic study. Archives of General Psychiatry, 48(3), 223-229.

Nelson, J. C., \& Charney, D. S. (1980). Primary affective disorder criteria and the endogenousreactive distinction. Archives of general psychiatry, 37(7), 787-793.

Nolen-Hoeksema, S., Parker, L.E., \& Larson, J. (1994). Ruminative coping with depressed mood following loss. Journal of Personality and Social Psychology, 67, 92-104

Owens, M. J., \& Nemeroff, C. B. (1991). Physiology and pharmacology of corticotropinreleasing factor. Pharmacol Rev, 43(4), 425-473.

Ozbay, F., Fitterling, H., Charney, D., \& Southwick, S. (2008). Social support and resilience to stress across the life span: a neurobiologic framework.Current psychiatry reports, 10(4), 
304-310.

Ozbay, F., Johnson, D. C., Dimoulas, E., Morgan, C. A., III, Charney, D., \& Southwick, S. (2007). Social Support and Resilience to Stress, Psychiatry (Edgmont), 4(5), 35-40.

Paykel, E. S. \& Cooper, Z. (1992). Life events and social stress. In: Handbook of Affective Disorders, 2nd Ed (ed E. S. Paykel), pp 149-170. Edinburgh: Churchill Livingston.

Paykel, E. S. (1994). Life events, social support and depression. Acta Psychiatrica Scandinavica, 89(s377), 50-58.

Paykel, E. S. (2003). Life events and affective disorders. Acta Psychiatrica Scandinavica, 108(s418), 61-66.

Pearlin, L. I. (1993). The social contexts of stress.

Penninx, B. W., Van Tilburg, T., Deeg, D. J., Kriegsman, D. M., Boeke, A. J. P., \& Van Eijk, J. T. (1997). Direct and buffer effects of social support and personal coping resources in individuals with arthritis. Social science \& medicine, 44(3), 393-402.

Pesonen, U. (2008). NPY L7P polymorphism and metabolic diseases.Regulatory peptides, 149(1), 51-55.

Peters, R. (2006). Ageing and the brain. Postgrad Med J, 82(964), 84-88.

Post, R. M. (1992). Transduction of psychosocial stress into the neurobiology of recurrent affective disorder. American Journal of Psychiatry, 149(8), 999-1010.

Post, R. M., Rubinow, D. R., \& Ballenger, J. C. (1984). Conditioning, sensitization, and kindling: Implications for the course of affective illness.Neurobiology of mood disorders, 1, 432466.

Preacher, K. J., Curran, P. J., \& Bauer, D. J. (2006). Computational tools for probing interactions in multiple linear regression, multilevel modeling, and latent curve analysis. Journal of 
educational and behavioral statistics, 31(4), 437-448.

Preacher, K. J., Rucker, D. D., \& Hayes, A. F. (2007). Addressing moderated mediation hypotheses: Theory, methods, and prescriptions. Multivariate behavioral research, 42(1), $185-227$.

Rasmusson, A. M, Vasek, J., Lipschitz, D. S., Vojvoda, D., Mustone, M. E., Shi, Q., Gudmundsen, G., Morgan, C. A., Wolfe, J., \& Charney, D. S. (2004). An increased capacity for adrenal DHEA release is associated with decreased avoidance and negative mood symptoms in women with PTSD. Neuropsychopharmacology, 29, 1546-1557

Redrobe, J. P., Dumont, Y., \& Quirion, R. (2002). Neuropeptide Y (NPY) and depression: from animal studies to the human condition. Life sciences, 71(25), 2921-2937.

Redrobe, J. P., Dumont, Y., Fournier, A., \& Quirion, R. (2002). The neuropeptide Y (NPY) Y1 receptor subtype mediates NPY-induced antidepressant-like activity in the mouse forced swimming test.

Redrobe, J. P., Dumont, Y., Herzog, H., \& Quirion, R. (2003). Neuropeptide Y (NPY) Y 2 receptors mediate behaviour in two animal models of anxiety: evidence from Y 2 receptor knockout mice. Behavioural brain research, 141(2), 251-255.

Roberts, R., Golding, J., Towell, T., \& Weinreb, I. (1999). The effects of economic circumstances on British students' mental and physical health.Journal of American College Health, 48(3), 103-109.

Rook, K. S. (1984). The negative side of social interaction: impact on psychological wellbeing. Journal of personality and social psychology, 46(5), 1097.

Rook, K. S. (1987). Social support versus companionship: effects on life stress, loneliness, and evaluations by others. Journal of personality and social psychology, 52(6), 1132. 
Rosal, M. C., King, J., Ma, Y., \& Reed, G. W. (2004). Stress, social support, and cortisol: inverse associations?. Behavioral Medicine, 30(1), 11-22.

Rosen, J. B., Schulkin, J. 1998. From normal fear to pathological anxiety. Psychol. Rev. 105, $325-50$

Russell, D. (1996). UCLA Loneliness Scale (Version 3): Reliability, validity, and factor structure. Journal of Personality Assessment, 66, 20-40.

Ryff, C. D. (1989). Happiness is everything, or is it? Explorations on the meaning of psychological well-being. Journal of personality and social psychology, 57(6), 1069.

Ryff, C. D., \& Keyes, C. L. M. (1995). The structure of psychological well-being revisited. Journal of personality and social psychology, 69(4), 719.

Sagone, E., \& De Caroli, M. E. (2014). Relationships between psychological well-being and resilience in middle and late adolescents. Procedia-Social and Behavioral Sciences, 141, 881-887.

Sajdyk, T. J., Shekhar, A., \& Gehlert, D. R. (2004). Interactions between NPY and CRF in the amygdala to regulate emotionality. Neuropeptides, 38(4), 225-234.

Sajdyk, T. J., Vandergriff, M. G., \& Gehlert, D. R. (1999). Amygdalar neuropeptide YY 1 receptors mediate the anxiolytic-like actions of neuropeptide $\mathrm{Y}$ in the social interaction test. European journal of pharmacology, 368(2), 143-147.

Saphire-Bernstein, S., Way, B. M., Kim, H. S., Sherman, D. K., \& Taylor, S. E. (2011). Oxytocin receptor gene (OXTR) is related to psychological resources.Proceedings of the National Academy of Sciences, 108(37), 15118-15122.

Sapolsky, R. M. (2001). Depression, antidepressants, and the shrinking hippocampus. Proceedings of the National Academy of Sciences, 98(22), 12320-12322. 
Sapolsky, R. M. (2003). Stress and plasticity in the limbic system. Neurochemical Research, $28(11), 1735-1742$.

Sax, L. J. (1997). Health trends among college freshmen. Journal of American College Health, $45(6), 252-262$.

Schrimshaw, E. W. (2003). Relationship-specific unsupportive social interactions and depressive symptoms among women living with HIV/AIDS: Direct and moderating effects. Journal of Behavioral Medicine, 26(4), 297-313.

Shafii, M., Steltz-Lenarsky, J., Derrick, A. M., Beckner, C., \& Whittinghill, J. R. (1988).

Comorbidity of mental disorders in the post-mortem diagnosis of completed suicide in children and adolescents. Journal of Affective Disorders,15(3), 227-233.

Shah, S. H., Freedman, N. J., Zhang, L., Crosslin, D. R., Stone, D. H., Haynes, C., ... \& Hauser, E. R. (2009). Neuropeptide Y gene polymorphisms confer risk of early-onset atherosclerosis. PLoS Genet, 5(1), e1000318.

Sheline, Y. I., Gado, M. H., \& Price, J. L. (1998). Amygdala core nuclei volumes are decreased in recurrent major depression. Neuroreport, 9(9), 2023-2028.

Sheline, Y. I., Sanghavi, M., Mintun, M. A., \& Gado, M. H. (1999). Depression duration but not age predicts hippocampal volume loss in medically healthy women with recurrent major depression. The Journal of neuroscience, 19(12), 5034-5043.

Sherry, S. T., Ward, M. H., Kholodov, M., Baker, J., Phan, L., Smigielski, E. M., \& Sirotkin, K. (2001). dbSNP: the NCBI database of genetic variation. Nucleic acids research, 29(1), 308-311.

Shively, C. A., Clarkson, T. B., \& Kaplan, J. R. (1989). Social deprivation and coronary artery atherosclerosis in female cynomolgus monkeys.Atherosclerosis, 77(1), 69-76. 
Sjöholm, L. K., Melas, P. A., Forsell, Y., \& Lavebratt, C. (2009). PreproNPY Pro7 protects against depression despite exposure to environmental risk factors. Journal of affective disorders, 118(1), 124-130.

Small, C. J., Morgan, D. G. A., Meeran, K., Heath, M. M., Gunn, I., Edwards, C. M. B., ... \& Bloom, S. R. (1997). Peptide analogue studies of the hypothalamic neuropeptide Y receptor mediating pituitary adrenocorticotrophic hormone release. Proceedings of the National Academy of Sciences, 94(21), 11686-11691.

Solberg, V. S., \& Viliarreal, P. (1997). Examination of self-efficacy, social support, and stress as predictors of psychological and physical distress among Hispanic college students. Hispanic Journal of Behavioral Sciences, 19(2), 182-201.

Sommer, W. H., Lidström, J., Sun, H., Passer, D., Eskay, R., Parker, S. C., ... \& Heilig, M. (2010). Human NPY promoter variation rs 16147: T $>$ C as a moderator of prefrontal NPY gene expression and negative affect. Human mutation, 31(8), E1594-E1608.

Sommer, W., Hyytiä, P., \& Kiianmaa, K. (2006). REVIEW: The alcohol-preferring AA and alcohol-avoiding ANA rats: neurobiology of the regulation of alcohol drinking. Addiction biology, 11(3-4), 289-309.

Song, Y. S., \& Ingram, K. M. (2002). Unsupportive social interactions, availability of social support, and coping: Their relationship to mood disturbance among African Americans living with HIV. Journal of Social and Personal Relationships, 19(1), 67-85.

Souri, H., \& Hasanirad, T. (2011). Relationship between resilience, optimism and psychological well-being in students of medicine. Procedia-Social and Behavioral Sciences, 30, 15411544.

Southwick, S. M., Ozbay, F., Charney, D., \& McEwen, B. S. (2008). Adaptation to stress and 
psychobiological mechanisms of resilience. Biobehavioral resilience to stress, 91-116.

Stansfeld, S. A., Fuhrer, R., Head, J., Ferrie, J., \& Shipley, M. (1997). Work and psychiatric disorder in the Whitehall II Study. Journal of psychosomatic research, 43(1), 73-81.

Steptoe, A., Owen, N., Kunz-Ebrecht, S. R., \& Brydon, L. (2004). Loneliness and neuroendocrine, cardiovascular, and inflammatory stress responses in middle-aged men and women. Psychoneuroendocrinology, 29(5), 593-611.

Stoudemire, A., Frank, R., Hedemark, N., Kamlet, M., \& Blazer, D. (1986). The economic burden of depression. General Hospital Psychiatry, 8(6), 387-394.

Swindle, R. W., Cronkite, R. C., \& Moos, R. H. (1989). Life stressors, social resources, coping, and the 4-year course of unipolar depression. Journal of Abnormal Psychology, 98(4), 468.

Tajfel, H., \& Turner, J. C. (1986). An integrative theory of intergoup relations. W: S. Worchell $i$ WG Austin (red.), Psychology of Intergroup Relations. Chicago, Nelson-Hall.

Tatemoto, K. (2004). Neuropeptide Y: history and overview. In Neuropeptide Y and Related Peptides (pp. 1-21). Springer Berlin Heidelberg.

Tennant, C. (2002). Life events, stress and depression: a review of recent findings. Australian and New Zealand Journal of Psychiatry, 36(2), 173-182.

Thorsell, A., Slawecki, C. J., El Khoury, A., Mathe, A. A., \& Ehlers, C. L. (2006). The effects of social isolation on neuropeptide $\mathrm{Y}$ levels, exploratory and anxiety-related behaviors in rats. Pharmacology Biochemistry and Behavior,83(1), 28-34.

Tschenett, A., Singewald, N., Carli, M., Balducci, C., Salchner, P., Vezzani, A., ... \& Sperk, G. (2003). Reduced anxiety and improved stress coping ability in mice lacking NPY-Y2 receptors. European Journal of Neuroscience, 18(1), 143-148.

Turner, J. \& Oakes, P. (1986). The significance of the social identity concept for social 
psychology with reference to individualism, interactionism and social influence. British Journal of Social Psychology, 25, 237-252.

Turner, J. C. Hogg, M. A., Oakes, P. J., Reicher, S. D., \& Wetherell, M. S. (1987). Rediscovering the social group: A self-categorization theory. Oxford, New York: Blackwell.

Turner, J. C., Oakes, P. J., Haslam, S. A., \& McGarty, C. A. (1994). Self and collective: Cognition and social context. Personality and Social Psychology Bulletin, 20, 454-463.

Turner, R. J. (1981). Social support as a contingency in psychological well-being. Journal of Health and Social Behavior, 357-367.

Uchino, B. N., Cacioppo, J. T., \& Kiecolt-Glaser, J. K. (1996). The relationship between social support and physiological processes: A review with emphasis on underlying mechanisms and implications for health. Psychol Bul, 119, 488-531.

Uher, R., \& McGuffin, P. (2008). The moderation by the serotonin transporter gene of environmental adversity in the aetiology of mental illness: review and methodological analysis. Molecular psychiatry, 13(2), 131-146.

Underwood, P. W. (2000). Social support: The promise and reality. In B. H. Rice (Ed.), Handbook of stress, coping and health ( pp. 367-391 ). Newbury Park, CA: Sage. Verger, P., Combes, J. B., Kovess-Masfety, V., Choquet, M., Guagliardo, V., Rouillon, F., \& Peretti-Wattel, P. (2009). Psychological distress in first year university students: socioeconomic and academic stressors, mastery and social support in young men and women. Social psychiatry and psychiatric epidemiology, 44(8), 643-650.

Wahlestedt, C., Pich, E. M., Koob, G. F., Yee, F., \& Heilig, M. (1993). Modulation of anxiety and neuropeptide Y-Y1 receptors by antisense oligodeoxynucleotides. Science, 259(5094), 528-531. 
Wang, P. S., Simon, G., \& Kessler, R. C. (2003). The economic burden of depression and the cost-effectiveness of treatment. International journal of methods in psychiatric research, 12(1), 22-33.

Webb, E., Ashton, C. H., Kelly, P., \& Kamali, F. (1996). Alcohol and drug use in UK university students. The lancet, 348(9032), 922-925.

Wells, K. B., Stewart, A., Hays, R. D., Burnam, M. A., Rogers, W., Daniels, M., ... \& Ware, J. (1989). The functioning and well-being of depressed patients: results from the Medical Outcomes Study. JAMA, 262(7), 914-919.

Westrin, Å., Ekman, R., \& Träskman-Bendz, L. (1999). Alterations of corticotropin releasing hormone $(\mathrm{CRH})$ and neuropeptide Y (NPY) plasma levels in mood disorder patients with a recent suicide attempt. European Neuropsychopharmacology, 9(3), 205-211.

Westrin, Å., Engstöm, G., Ekman, R., \& Träskman-Bendz, L. (1998). Correlations between plasma-neuropeptides and temperament dimensions differ between suicidal patients and healthy controls. Journal of Affective Disorders,49(1), 45-54.

Widdowson, P. S., Ordway, G. A., \& Halaris, A. E. (1992). Reduced neuropeptide Y concentrations in suicide brain. Journal of neurochemistry, 59(1), 73-80.

Widerlov, E., Lindstrom, L. H., Wahlestedt, C., \& Ekman, R. (1988). Neuropeptide Y and peptide YY as possible cerebrospinal fluid markers for major depression and schizophrenia, respectively. Journal of Psychiatric Research, 22(1), 69-79.

Wintre, M. G., \& Sugar, L. A. (2000). Relationships with parents, personality, and the university transition. Journal of College Student Development.

Wintre, M. G., \& Yaffe, M. (2000). First-year students' adjustment to university life as a function of relationships with parents. Journal of adolescent research,15(1), 9-37. 
Wolkowitz, O. M., Reus, V. I., Chan, T., Manfredi, F., Raum, W., Johnson, R., \& Canick, J. (1999). Antiglucocorticoid treatment of depression: double-blind ketoconazole. Biological psychiatry, 45(8), 1070-1074.

Wolpe, J. (1981). The dichotomy between classical conditioned and cognitively learned anxiety. Journal of Behavior Therapy and Experimental Psychiatry,12(1), 35-42.

Wu, G., Feder, A., Wegener, G., Bailey, C., Saxena, S., Charney, D., \& Mathé, A. A. (2011). Central functions of neuropeptide $\mathrm{Y}$ in mood and anxiety disorders. Expert opinion on therapeutic targets, 15(11), 1317-1331.

Wu, Q., Wen, T., Lee, G., Park, J. H., Cai, H. N., \& Shen, P. (2003). Developmental control of foraging and social behavior by the Drosophila neuropeptide Y-like system. Neuron, 39(1), 147-161.

Yaacob, S. N., Juhari, R., Talib, M. A., \& Uba, I. (2009). Loneliness, stress, self esteem and depression among Malaysian adolescents. Journal Kemanusiaan, 14.

Yanos, P. T., Rosenfield, S., \& Horwitz, A. V. (2001). Negative and supportive social interactions and quality of life among persons diagnosed with severe mental illness. Community mental health journal, 37(5), 405-419.

Yeh, C. J., \& Inose, M. (2003). International students' reported English fluency, social support satisfaction, and social connectedness as predictors of acculturative stress. Counselling Psychology Quarterly, 16(1), 15-28.

Zametkin, A. J., Alter, M. R., \& Yemini, T. (2001). Suicide in teenagers: assessment, management, and prevention. JAMA, 286(24), 3120-3125.

Zarrett, N., \& Eccles, J. (2006). The passage to adulthood: Challenges of late adolescence. New directions for youth development, 2006(111), 13-28. 
Zhou, Z., Zhu, G., Hariri, A.R., Enoch, M., Scott, D., Sinha, R., Virkkunen, M., Mash, D.C., Lipsky, R.H., Hu, X., Hodgkinson, C.A., Xu, K., Buzas, B., Yuan, Q., Shen, P., Ferrell, R.E., Manuck, S.B., Brown, S.M., Hauger, R.L., Stohler, C.S., Zubieta, J., \& Goldman, D. (2008). Genetic variation in human NPY expression affects stress response and emotion. Nature, 452, 997-1001.

Zimet, G. D., Dahlem, N. W., Zimet, S. G., \& Farley, G. K. (1988). The multidimensional scale of perceived social support. Journal of personality assessment, 52(1), 30-41. 


\section{Appendix A}

\section{Recruitment Notice}

Study Title: Social Identity and Resilience

Abstract: This study assesses your social identity and coping abilities to determine how they contribute to your resiliency to the harmful effects of stressful events.

Description: The purpose of this study is to examine the factors that aid in your resilience to the negative health effects of stressful events. Additionally, we want to assess the social resources that you may have to help during stressful events (e.g., support from parents and peers). We are also interested in examining your stress management abilities (e.g., coping strategies and flexibility) and mood (e.g., depression and anxiety) and how these may be related to your well-being.

You will be asked to provide one saliva sample, and fill out questionnaires; some of the questions are of a sensitive nature in this study as we will be asking you personal questions which may cause discomfort. The study will take approximately $75 \mathrm{~min}$ to complete.

***Please DO NOT eat, drink (other than water) or smoke 30 minutes prior to the experiment***

This study has received clearance by the Carleton University Psychology Research Ethics Board (Reference \#__ ).

Eligibility: First year undergraduate student at Carleton University, who can receive experimental credits for participation and are under the age of 30 .

Compensation: $1.25 \%$ towards any eligible SONA course 


\title{
Appendix B
}

\section{Informed Consent}

The purpose of an informed consent is to ensure that you understand the purpose of the study and the nature of your involvement. The informed consent has to provide sufficient information such that you have the opportunity to determine whether you wish to participate in the study.

\section{Study title: Social Identity and Resilience}

\section{Contacts}

The following people are involved in this research project and may be contacted at any time if you have further questions about this project, what it means, or concerns about how it was conducted:

\author{
Ajani Asokumar, Graduate Researcher, Department of Neuroscience \\ Dr. Kim Matheson, Faculty Member, Department of Psychology \\ Phone: 613 520-2699, kim.matheson@carleton.ca \\ Dr. Hymie Anisman, Faculty Member, Department of Neuroscience \\ Phone: 613 520-3570, hymie_anisman@carleton.ca
}

Should you have any ethical concerns about this research, please contact Dr. Shelley Brown at: shelley.brown@carleton.ca (613-520-2600 ext. 1505). For any other concerns, please contact Dr. Joanne Pozzulo (Chair, Department of Psychology, 613-520-2600, ext. 1412, psychchairecarleton.ca).

\section{Study Personnel:}

Ajani Asokumar, Graduate Researcher, Department of Neuroscience

Dr. Kim Matheson, Faculty Member, Department of Psychology

Dr. Hymie Anisman, Faculty Member, Department of Neuroscience

Purpose: The purpose of this study is to assess the factors that contribute to your resilience to the negative experience of stressful events. We will be evaluating the various social resources that you may use to cope with potentially stressful events (e.g., support from parents and peers). We are also interested in examining your stress management abilities (e.g., coping strategies and flexibility) and mood (e.g., depression and anxiety). Further, it is also of interest to examine your sense of belongingness and feelings of well-being. In addition, we are interested in looking at how genes may relate to your well-being and to determine the presence or absence of particular genes. By understanding the genetic and psychosocial factors that lead to different mood outcomes, we will gain a better understanding of how mood changes develop. This research will therefore help to develop improved approaches to both treat, and prevent mood disorders in the future. 


\section{What are we asking you to do?}

We will be asking you to fill out a number of questionnaires regarding information related to your background (e.g., demographic, family, city of residence), medical history (e.g., current medications and history of illnesses and psychological disorders), stress management (e.g., coping styles), mood (e.g., feelings of depression and anxiety), sense of well-being, and the quality of your interpersonal relationships (e.g., social support, group identities).

We are also asking participants to provide a DNA sample through the simple act of spitting into a tube however, due to the relatively large volume of saliva required $(\sim 1 \mathrm{ml})$ this can take up to 5 minutes. This study should take approximately 75 minutes to complete.

\section{What will I receive for my participation?}

Within 1 week after completion of the study you will be assigned $1.25 \%$ course credit.

\section{Potential risks or causes of discomfort for participants}

There are no physical risks in this study. There may be some discomfort or anxiety experienced when responding to some questions of a sensitive nature in this study. We will be asking you to fill out questionnaires related to stress management, interpersonal relationships with family and friends, and feelings of well-being. If this is the case, the Debriefing form at the end of the study contains contact information for people who are available to help. You can also choose to withdraw from the study at any point. We are looking to collect a saliva sample, which may take up to 5 minutes. Some participants may therefore feel discomfort or embarrassment about spitting into a tube in the presence of the researcher and other students, in which case you may feel free to leave the room and finish the sample. You will be asked to not drink, eat, smoke or chew gum for 30 minutes before providing this sample.

\section{Anonymity and confidentiality}

All information and samples collected from you for this study will be identified with a code number, as opposed to any personal identifiers such as your name or address. We will maintain a separate record that matches your personal identification details with this code number. This is necessary in order for us to re-contact you in the future (with your express permission to do so), and so that we can respect your right to withdraw from the study at a later date (to be described below). However, this record that allows your identity to be linked to your information will kept in a separate and secured location, and will only be accessible to the researchers, in order to maintain anonymity and confidentiality of your information. All personal identifying information will be destroyed within 3 years of collection. All information is stored on a server only accessible by this research lab.

\section{Genetic testing: Common questions and concerns What is DNA?}

DNA is a large molecule that contains information necessary for our bodies to build all the components needed for our development, growth and survival. This information is commonly referred to as the genetic code or the DNA sequence. Some rare diseases can be attributed entirely to simple errors in our DNA sequence. However, the majority of common diseases (including depression) are caused by a combination of many different genetic factors, together with environmental factors (how we grew up, life events, etc). 
What will my DNA be used for?

If you compare any two people, their DNA will be about $99 \%$ identical. We are interested in the $1 \%$ of DNA that is different between people. Our current plan is to investigate these differences, focusing on just a small proportion of your genes (we are targeting less than 100 of the $\sim 30,000$ genes that humans have) which we anticipate may be involved in risk of either anxiety or depression.

We are also planning future follow-up studies on your DNA, which will extend the analysis to substantially more genes - potentially all genes. Based on the results of the current study, there could be future interactions that may be of interest to study further including but not limited to: relationships between serotonin and depression as well as between neuropeptide $\mathrm{Y}$ and resilience, interactions between oxytocin and dopamine as well as other related genes which could be significant to positive outcomes related to social factors. These future studies will be limited to analyses of the DNA molecule and the genetic code, and will not involve any other use or manipulation of your DNA sample. At the end of this form, you have the option to opt-out of any such future uses of your DNA sample.

\section{How long will my DNA be stored, and potentially used in research?}

By providing a DNA sample and signing this form, you are indicating that you are willing for us to preserve and analyze your DNA sample for an extended period of time (3 years or less). During this period, use of the sample is guaranteed to be limited to studies that read the DNA molecule. Your saliva and any DNA samples will be destroyed, by incineration, no later than 3 years after saliva was collected.

\section{Will I be told the results of my own genetic analysis?}

No. Your DNA sample and genetic information will be identified by a code number, and not your name. This preserves confidentiality of this information. Returning your personal genetic information to you would require that confidentiality be compromised, so will be avoided. Furthermore, genetic data collected in this study will not allow accurate prediction of whether or not you will develop any disease. Although in the future we hope to be able to use genetic materials to examine disease susceptibility, our research is in a preliminary phase and we are not currently able to provide this kind of information on an individual basis.

\section{Can my DNA ever be used to identify me?}

This is a complicated question to answer. Unless you have an identical twin (whose DNA will be identical to yours), your DNA is absolutely unique to you. It is this unique nature of genetic material that allows individuals to be identified based entirely on their DNA, through techniques such as DNA fingerprinting. It is therefore theoretically possible that in the future, your identity could be determined from simply analyzing your DNA sample.

It is extremely unlikely, however, that you could be identified based on your DNA sample. In order to identify you based purely on your DNA sample, it would be necessary to compare your DNA sample that you provide today, with another DNA sample from you in a DNA database, which is linked to your identity. DNA databases do exist in countries including Canada, Australia, USA and UK, but are limited to samples from criminal offenders. Access to these databases is strictly limited to law enforcement agencies thus cannot be accessed by researchers. Access to DNA samples taken for this study will similarly be limited to the researchers, and will not be provided to any law enforcement agency unless we become legally obliged to do so (to our knowledge, this has never happened to any research group). Furthermore, these government 
DNA databases typically contain information about only 13 regions of human DNA, none of which are to be analyzed in the present study.

\section{If you have any additional questions or concerns, please ask the researcher today, or contact any of the principal investigators at a later date.}

\section{Right to withdraw from this study}

Participation in this study is entirely voluntary. At any point during the study you have the right to not complete certain questions or to withdraw with no penalty whatsoever and compensation will still be granted. Furthermore, if at a later date you wish to withdraw from the study, you can contact the principal investigators and we will destroy all of your records (questionnaire answers, responses from the interview, plus DNA sample) from this study. The only exception is where data has already been published. In this instance, unpublished data plus your DNA sample will be destroyed.

\section{Declaration of consent}

To use your DNA for any future research studies that are aimed at analyzing DNA sequence, please indicate below how you would like your sample to be treated in the future by selecting one of the three options. There are no obligations or penalties for you associated with your selection.

Option 1: Use of my DNA/saliva sample must be strictly limited to the analysis of $<100$ genes, as described in the current research plan. This can only be done within a 3 year period of my saliva being collected.

Option 2: I grant the researcher permission to re-contact me to seek consent to use my DNA/saliva samples in future research studies.

Email: Phone Number:

Option 3: I grant the researcher permission to use my DNA/saliva samples for any future research studies, limited to analyses of the DNA molecule.

This study has been cleared by the Carleton University Psychology Research Ethics Board (Ethics \# 14-121)

Signatures

I have read the above form and understand the conditions of my participation. My participation in this study is voluntary, and I understand that if at any time I wish to leave the experiment, I may do so without having to give an explanation and with no penalty whatsoever. Furthermore, I am also aware that the data gathered in this study are confidential and anonymous with respect to my personal identity. My signature indicates that I agree to participate in this study.

Participant's Full Name: Participant's Signature:

Researcher's Name: Researcher's Signature:

Date: 


\section{Appendix C}

\section{Written Debriefing}

What are we trying to learn in this research?

Individuals are faced with a variety of stressful events over the course of their life, and these types of events may have important consequences for one's well-being. One such stressor is the start of one's university career. The experience of stressors can be buffered by the quality of relationships and group-ties you may have as an adult, your coping abilities, and perceived social support. Recently, there have been research efforts made to better understand the association between one's stress management abilities and depressive and anxiety symptoms. Specifically, individuals who are better able to appraise stressful events and are able to use various and appropriate coping strategies tend to report decreased levels of stress and less frequent reports of emotional and physical distress. Therefore, it is possible that one can be more resilient to the impact of life stressors based on the relationship between one's social identity and stress management abilities. A decreased level of resilience factors may lead to higher depression and anxiety symptoms. Additionally, when under distress, our relationships to those around us may be crucial to our well-being, and may be influenced by the type of support we receive. For instance, experiencing unsupportive social interactions may lead to greater feelings of anxiety, whereas these feelings may be decreased by social support. Recently research has focused on important genetic factors which may underlie variations in resilience levels and increase susceptibility to develop depression and anxiety related illnesses.

In addition to the questionnaires, you were asked to provide a saliva sample. Genetic material (e.g., DNA) can be extracted from our saliva. Therefore we were interested in examining the relationships between your responses on some of the questionnaires (e.g., social identity and depressive symptoms) and certain genes (genes make up our DNA and may code for different traits such as, eye color). Multiple forms of the same gene are present within the population, wherein one or more forms of the gene might be related to our well-being (e.g., depression). You were asked to provide a saliva sample, genetic material (e.g., DNA) can be extracted from this saliva sample. Therefore we were interested in examining the relationships between your responses on some of the questionnaires (e.g., sense of well-being, depressive symptoms) and certain genes.

In this study, we are interested in examining the relationships between your group identity and how this influences your perceived social support, stress management abilities, and overall sense of well-being. As well as, how some genetic factors might relate to various factors of resilience and prosocial behaviours. We are also interested in examining the relationship between different forms of genes and how these may make an individual more or less susceptible to mental health related illnesses. We hope that this research will determine what factors may influence one's resilience to the harmful physical and mental health effects of stressful events.

What if I have questions later?

Please contact

Ajani Asokumar, Graduate Researcher 
Dr. Kim Matheson, Faculty Member

Phone: 613 520-2699, kim.matheson@carleton.ca

Dr. Hymie Anisman, Faculty Member

Phone: 613 520-3570, hymie_anisman@carleton.ca

Ethical concerns: Dr. Shelley Brown, Chair of Carleton University Ethics Committee for Psychological Research, 613-520 2600 ext. 1505, shelley.brown@carleton.ca

Any other concerns: For any other concerns, please contact Dr. Joanne Pozzulo (Chair, Department of Psychology, 613-520-2600, ext. 1412, psychchair@carleton.ca)

Is there anything that I can do if I found this experiment to be emotionally draining?

Thank you very much for your participation in this study. If you feel any distress at the moment, from related to answering some of the personal questions during this study, you should be aware that these are legitimate feelings and it is understandable that thinking about past stressful experiences can induce feelings of distress. If you are experiencing any distress from completing these measures, please consult the resources below:

Carleton University Health and Counseling Services at: 613-520-6674,

Ottawa Distress Centre: (613) 238 1089, Web Site: www.dcottawa.on.ca.

Mental Health Crisis Line: within Ottawa (613) 722-6914, outside Ottawa 1-866-996-0991, Web Site: http://www.crisisline.ca/

Want to know more about this subject? You can read the following studies by going to these links below:

http://www.ncbi.nlm.nih.gov/pmc/articles/PMC2795557/

http://www.sciencemag.org/content/328/5984/1408.short 


\section{Appendix D}

\section{Background Information}

The purpose of the following set of questions is to collect demographic information about various aspects of your life. Although some of the questions may seem unrelated to the present study (e.g. weight, height, religion, etc...) these factors may be important determinants of your health and well-being.

1. Sex: Female/ Male (please select one)

2. Age:

3. What is your citizenship status?

\section{Canadian citizen}

\begin{tabular}{lll}
\hline Landed immigrant & Since what year? & Country of origin \\
Student visa & Since what year? & Country of origin \\
Temporary visa & Since what year? & Country of origin \\
Refugee & Since what year? & Country of origin \\
\hline
\end{tabular}

4. What is your first language?

If your first language is not English, how long have you been fluent in reading, writing and comprehension of the English language?

5. What is your ethnic/racial background? Please select the one that best applies to you.

Asian (e.g., Chinese, Japanese, Korean)

South Asian (e.g., East Indian, Pakistani, Punjabi, Tamil, Sri Lankan)

South East Asian (e.g., Cambodian, Indonesian, Laotian)

Arab/West Asian (e.g., Armenian, Egyptian, Iranian, Lebanese, Moroccan)

Black (e.g., African, Haitian, Jamaican, Somali)

Latin American/Hispanic

Aboriginal

White/Euro-Caucasian

Other (please specify): 
6. What is your religious affiliation? Please select the one that best applies to you.

None-Atheist (e.g., belief that there is NO God)

None-Agnostic (e.g., belief that the existence of God cannot be known)

Protestant (e.g., United, Anglican, Baptist, Presbyterian, Lutheran, Pentecostal, Mennonite,"Christian")

Catholic (e.g., Roman Catholic, Ukrainian Catholic)

Jewish

Muslim

Buddhist

Hindu

Sikh

Bahá'í

Other (please specify):

7. How long have you been a resident of Ottawa, Ontario?

8. If you just moved to Ottawa to attend University, how far is your former place of residence? I was already living in Ottawa before attending Carleton University

Less than an hour from Ottawa

$1+$ hour from Ottawa

$3+$ hours from Ottawa

$5+$ hours from Ottawa...... Please specify the city

Outside of Ontario/Quebec...... Please specify the province

Outside of Canada...... Please specify the country

9. If you just moved to Ottawa to attend University, how long did you live in your former place of residence?

10. If you just moved to Ottawa, how often do you do you go back to your former place of residence?

11. If you just moved to Ottawa, have you been away from home before? YES NO

If YES, please indicate how often: and for how long: 
12. What is your current living arrangement? Please select the one that best applies to you. Living alone in residence (at Carleton University)

Living alone off-campus

Living with friends in residence (at Carleton University)

Living with friends off-campus

Living with roommates in residence (at Carleton University)

Living with roommates off-campus

Living with parents

Living with spouse/significant other

Living with spouse/significant other and young children (13 years and younger)

Living with spouse/significant other and older children (13 years and older)

Living alone with young children (13 years and younger)

Living alone with older children (13 years and older)

Other (please specify)

13. Do you have any relatives or close friends in Ottawa?

YES

If YES, how many?

14. What is your current relationship status? Please select the one that best applies to you.

Single, and not seeing anyone

Going out with someone

In a serious dating relationship

Have recently broken up ... Please specify how many weeks ago you broke up

Living with an intimate other

Engaged

Married

Separated/Divorced ....... Please specify how many months ago you separated Widowed

15. Is your current (or most recent) partner: Male

OR Female ?

16. Please provide your current height: Please provide your current weight:

(ft) $\mathrm{OR}$ (lb) OR (metres) (kg) 
17. What level of education have you completed?

8 years or less of elementary school

some high school but no diploma

a high school diploma or equivalent

1 to 3 years of college/university (including study at a technical college or CEGEP)

an undergraduate university degree

a master's degree

a doctoral degree

a professional degree [medicine (M.D.), dentistry (D.D.S.), law, etc.]

18. Have you had or do you currently have any health related (i.e., medical) illnesses or physical conditions? Please select the one that best applies to you.

NO, I don't

YES, I did but I no longer do

YES, I do

If YES, please specify illness/condition you had/have

If YES, please specify any current treatment you are receiving

19. Do you currently have a psychological disorder/condition (e.g. depression, anxiety, etc.)? NO, I don't

YES, I do

If YES, please specify disorder/condition

If YES, are you currently being treated for this disorder/condition?

NO, I'm not

YES I am

If YES, please specify treatment type (e.g. medications, therapy). 
20. Have you ever in the past had a psychological disorder/condition (e.g. depression, anxiety, etc.) but no longer do?

NO, I haven't

YES, I have

If YES, please specify the disorder/condition you had

21. In your opinion, how would you describe your health?

Poor

Fair

Good

Very good

Excellent

22. Are you on any of the following medications (please check all that apply)?

Anti-inflammatories (please specify)

Anti-depressants (please specify)

Anti-anxieties (please specify)

Allergy medication (please specify)

Other prescription drugs (please specify)

23. What is your estimate of your family's gross income per year? Please select the one that best applies to you. under $\$ 15,000$

$\$ 15,000$ - \$29,999

$\$ 30,000-\$ 44,999$

$\$ 45,000$ - $\$ 59,999$

$\$ 60,000$ - $\$ 74,999$

$\$ 75,000-\$ 89,999$

$\$ 90,000$ - \$104,999

$\$ 105,000$ or more

24. What is your employment status?

Employed Part-time

Employed Full-time

Unemployed

Retired

Other : 


\section{Appendix E}

\section{Beck Depression Inventory (BDI)- 21 item scale}

On this questionnaire are groups of statements. Please read the entire group of statements in each category. Then pick out ONE statement in that group which best describes the way you feel. Check off the number beside the statement you have chosen.

1. $\quad 0 \quad=\mathrm{I}$ do not feel sad

$1=$ I feel sad or blue

$2 \mathrm{a}=\mathrm{I}$ am blue or sad all of the time and I can't snap out of it

$2 \mathrm{~b}=\mathrm{I}$ am so sad or unhappy that it is very painful

3 = I am so sad or unhappy that I can't stand it

2. $\_$_ $0=$ I am not particularly pessimistic or discouraged about the future

$1=$ I feel discouraged about the future

$2 \mathrm{a}=$ I feel I have nothing to look forward to

$2 b=$ I feel I won't ever get over my troubles

3 = I feel that the future is hopeless and things cannot improve

3. $\quad 0=$ I do not feel like a failure

1 = I feel I have failed more than the average person

_ $2 \mathrm{a}=\mathrm{I}$ feel I have accomplished very little that is worthwhile or that means anything $2 \mathrm{~b}=$ As I look back on my life, all I can see is a lot of failures

_ $3=$ I feel I am a complete failure as a person

4. $\quad 0=$ I am not particularly dissatisfied

$1 \mathrm{a}=\mathrm{I}$ feel bored most of the time

$1 \mathrm{~b}=\mathrm{I}$ don't enjoy things the way I used to

- 2 = I don't get satisfaction out of anything anymore

$3=\mathrm{I}$ am dissatisfied with everything

5. $\quad 0=$ I don't feel particularly guilty

1 - 1 I feel bad or unworthy a good part of the time

$2 \mathrm{a}=\mathrm{I}$ feel quite guilty

$2 b=$ I feel bad or unworthy practically all of the time now

$3=$ I feel as though I am very bad or worthless

6. $\quad 0=$ I don't feel I am being punished

1 = I have a feeling that something bad may happen to me

$2=$ I feel I am being punished or will be punished

$3 \mathrm{a}=\mathrm{I}$ feel I deserve to be punished

$3 b=I$ want to be punished 
7. 0 _ 0 I don't feel disappointed in myself

$1 \mathrm{a}=\mathrm{I}$ am disappointed in myself

$1 \mathrm{~b}=$ I don't like myself

$2=$ I am disgusted with myself

$3=$ I hate myself

8. _ _ $0=$ I do not feel I am any worse than anybody else

$1=$ I am very critical of myself for my weaknesses or mistakes

$2 \mathrm{a}=$ I blame myself for everything that goes wrong

$2 \mathrm{~b}=\mathrm{I}$ feel I have many bad faults

$9 \_0$ _ I don't have thoughts of harming myself

$1=$ I have thoughts of harming myself but I would not carry them out

$2 \mathrm{a}=\mathrm{I}$ feel I would be better off dead

$2 \mathrm{~b}=\mathrm{I}$ have definite plans about committing suicide

$2 \mathrm{c}=\mathrm{I}$ feel my family would be better off if I were dead

3 = I would kill myself if I could

10. $0=$ I don't cry anymore than usual

$1=$ I cry more now than I used to

2 = I cry all the time now. I can't stop it

3 = I used to be able to cry but now I can't cry at all even though I want to

11. 0 _ 0 I am no more irritable than usual

$1=$ I am more irritable than usual

$2=$ I am much more irritable than usual

$3=$ I am irritable all the time

12. 0 _ 0 I have not lost interest in other people

$1=\mathrm{I}$ am less interested in other people than I used to be

2 = I have lost most of my interest in other people and I have little feeling for them

3 = I have lost all my interest in other people and don't care about them at all

13. $0=$ I make decisions about as well as ever

$1=$ I am less sure of myself now and try to put off making decisions

$2=$ I can't make decisions anymore without help

3 = I can't make decisions at all anymore

14. $0=$ I don't feel I look any worse than I used to

$1=\mathrm{I}$ am worried that I am looking old or unattractive

$2=$ I feel that there are permanent changes in my appearance and they make me look unattractive

3 = I feel that I am ugly or repulsive looking 
15. _ $0=$ I can work about as well as before

$1 \mathrm{a}=$ It takes extra effort to get started at doing something

$1 \mathrm{~b}=\mathrm{I}$ don't work as well as I used to

$2=$ I have to push myself very hard to do anything

$3=$ I can't do any work at all

16. $0=$ I can sleep as well as usual

$1=$ I wake up more tired in the morning than I used to

$2=$ I wake up 1-2 hours earlier than usual and find it hard to get back to sleep

$3=$ I wake up early every day and can't get more than 5 hours sleep

17. _ $0=\mathrm{I}$ don't get anymore tired than usual

$1=\mathrm{I}$ get tired more easily than I used to

— 2 = I get tired from doing anything

— $3=$ I get too tired to do anything

18. _ $0=$ My appetite is no worse than usual

- $1=$ My appetite is not as good as it used to be

— 2 - My appetite is much worse now

3 - I have no appetite at all any more

19.__ 0 = I haven't lost much weight, if any, lately

$1=$ I have lost more than 5 pounds

— 2 = I have lost more than 10 pounds

3 = I have lost more than 15 pounds

20. _ $0=\mathrm{I}$ am no more concerned about my health than usual

$1=\mathrm{I}$ am concerned about aches and pains or upset stomach or constipation or other unpleasant feelings in my body

$2=\mathrm{I}$ am so concerned with how I feel or what I feel that it's hard to think of much else 3 = I am completely absorbed in what I feel

21. _ 0 = I have not noticed any recent change in my interest in sex

$1=\mathrm{I}$ am less interested in sex than I used to be

$2=\mathrm{I}$ am much less interested in sex now

$3=$ I have lost interest in sex completely 


\section{Appendix F}

Additional Debriefing

(This debriefing will be provided to those who select $2 \mathrm{a}$ or higher on question 9 of the BDI)

Depression is a condition that can occur for many reasons, including workplace, school, or relationship stressors, traumatic life events, discrimination, as well as physical/biological imbalances. Approximately $10-15 \%$ of people will suffer some degree of depression during their lifetime. With advances in modern medicine, most people can readily be treated for this illness, which if unattended can be long lasting and affect many aspects of one's life. The symptoms of depression comprise:

- Poor or depressed mood, or a reduction in the pleasure gained from otherwise positive experiences

- $\quad$ Sleep disturbances

- Eating disturbances (loss of appetite, or overeating despite not being hungry), which may be linked to weight changes

- Lack of sexual interest

- Fatigue and lethargy (you don't feel like doing anything)

- An inability to focus (e.g., you have a hard time reading)

- Reduced interactions with family and friends

- Thoughts of suicide

Someone who is depressed may experience several (3-4), but not necessarily all of the above symptoms.

It is likewise the case that $60 \%$ of individuals will encounter a severe traumatic event in their lives and of these people, a fair number will develop symptoms that cause severe anxiety.

Illnesses of this nature, including posttraumatic stress disorder (PTSD) can be treated. Once again, if unattended, the repercussions can be severe. Symptoms include:

- Hyperarousal (e.g., feelings of anxiety and reactivity even to minor situations)

- Intrusive thoughts (memories of the event come into your head frequently)

- Avoiding thoughts or stimuli related to the event

These symptoms can persist for more than a month following the event, and influence your dayto-day functioning.

Your responses to this survey suggest that you may be experiencing one of the above disorders. If you are not already receiving attention for this problem, it is suggested that you contact your family physician. It is not a good idea to allow problems to fester, as ruminating over these problems will typically not make them go away. Your family physician or counsellor will usually be able to help you or to refer you to someone who can. If you do not have a family physician, then you can contact either of the following:

Mental Health Crisis Line: within Ottawa (613) 722-6914, outside Ottawa 1-866-996-0991, Web Site: http://www.crisisline.ca/

Ottawa Distress Centre: (613) 238 1089, Web Site: www.dcottawa.on.ca 


\section{Appendix G}

\section{Suicidal Ideation Protocol}

\section{$\underline{\text { IN-PERSON/TELEPHONE SITUATIONS }}$}

Item 9 (from 21-item version; Item 7 on 13-item version) on the Beck is checked immediately (e.g., while getting credit information and debriefing ready).

If the Beck 9 is 0 or 1 , nothing is done except give credit and debriefing. The debriefing includes a summary of the goals of the study as well as a list of contact numbers (e.g., Health and Counseling Services).

If the Beck 9 is a 2a, the participant is reminded of counseling services available at Carleton, and in the community. Credit and debriefing are subsequently given. If there are many participants (group questionnaire setting) and it is not feasible to remind the participant privately in the study room of services, then the participant will be taken to a private room, with the researcher saying that they are being taken to be debriefed, and they will be reminded of services available there. Credit and debriefing sheet are provided.

\section{If the Beck 9 is $2 b$, c or 3:}

If possible, the participant is spoken to privately. If speaking with the participant privately in the study room is not feasible (group setting), then the participant will be taken to a private room, with the researcher saying they are being taken to be debriefed. The researcher will state that they have noticed the Beck item, and that they are concerned about their welfare. The summarized seven-step protocol (below) is then implemented. The summarized seven-step protocol (below) is then implemented.

The following will be assessed:

1. The length of time that participant has had suicidal thoughts.

2. Whether the participant has talked to anyone regarding these thoughts.

3. Whether the participant is currently seeing a therapist.

4. Whether the participant has a plan and the means to carry out their plan

5. Whether the thought to carry out their plan is imminent

6. If plan is imminent then the protocol outlined below will be followed.

\section{NOTE: Keep a written record documenting the assessment.}

\section{ADDITIONAL DETAILS:}

The plan and means. The participant is questioned about the plan and the means to carry out this plan. Examples of plans are such things as taking large amounts of painkillers, and means are having lots of painkillers available. You don't have to give examples of plans, just ask whether they have thought about how they would do it.

If there are no plans, or there are plans but no means (e.g., take painkillers but none around), 
remind the participant of counseling services available in the community and also the ER at the hospital. If the participant is also seeing a therapist, it is suggested that the participant speak with the therapist about this. Then the credit and debriefing are given.

If there are both plans and means, the participant is asked whether thoughts to carry out this plan are imminent (that is, are they thinking of doing this very soon? For example, within the next day).

If not imminent, OR have plans and means but don't think they would carry them out (e.g., yes, I've thought about doing it occasionally and have the meds but realize I could not go through with it), the participant is reminded of counseling services available in the community, and also the ER at the hospital. If also seeing a therapist, it is suggested that the participant speak with their therapist about this. Then the credit and debriefing are given.

If means are available and plan is imminent, and there is good reason to believe that then individual may in fact carry out the suicidal thoughts soon, then the participant is informed that you will be calling 911 because you are very concerned that they will harm themselves. During the 911 call, the police are informed of the individual's imminent intent to commit suicide. The person's name and phone are given to the police. This step involves breaking confidentiality, but the welfare of the participant takes priority (APA and CPA and Tri-Council guideline 3.1). 911 will take it from there. The situation is documented, and your supervisor and ethics chair are contacted.

\section{Things NOT TO DO in both in-person and telephone situations}

Do not give out your lab number as a resource for somewhere to call for help.

\section{Do not give out home phone numbers of research personnel.}

Do not intervene directly with the participant. That is, do not escort the person to the hospital or health services. If a participant does call the lab for help, refer them again to the resources, such as Health Services or the Distress Centre or hospital. Assess for immediacy of suicidal intention, and follow the steps outlined above, such as finding out if there is someone else there, calling 911 directly if there is imminent suicidal intent, etc.

Do not engage in a helping relationship with the person. Provide the information about resources, but, for example, do not make follow-up calls to check up on the person and see how they are doing.

Do not do any of this assessment and suicidal screening if you do not feel confident about it. Refer it to your supervisor.

BDI item 9

9. $0=$ I don't have thoughts of harming myself

$1=$ I have thoughts of harming myself but I would not carry them out

$2 \mathrm{a}=\mathrm{I}$ feel I would be better off dead

$2 \mathrm{~b}=\mathrm{I}$ have definite plans about committing suicide

$2 \mathrm{c}=\mathrm{I}$ feel my family would be better off if I were dead

3 = I would kill myself if I could 


\section{Appendix H}

\section{Ryff's Well-Being Scales}

\begin{tabular}{|c|c|c|c|c|c|}
\hline \multicolumn{6}{|c|}{ AUTONOMY } \\
\hline Strongly & Moderately & Slightly & Slightly & Moderately & Strongly \\
\hline Disagree & Disagree & Disagree & Agree & Agree & Agree \\
\hline 1 & 2 & 3 & 4 & 5 & 6 \\
\hline etimes I cl & le wa & hink & 1 & 3 & 5 \\
\hline
\end{tabular}
to be more like those around me.

2. I am not afraid to voice my opinions, even when they are in opposition to the opinions of most people.

3. My decisions are not usually influenced by what everyone else is doing.
1
2
34
$5 \quad 6$

I tend to worry about what other people think of me.

$\begin{array}{llllll}1 & 2 & 3 & 4 & 5 & 6\end{array}$

5. Being happy with myself is more important to me than having others approve of me.

$\begin{array}{lllllll}1 & 2 & 3 & 4 & 5 & 6\end{array}$

6. I tend to be influenced by people with strong opinions.

7. People rarely talk me into doing things I don't $\quad \begin{array}{llllllllll} & 1 & 2 & 3 & 4 & 5 & 6\end{array}$ want to do.

8. It is more important to me to "fit in" with others than to stand alone on my principles.

9. I have confidence in my opinions, even if they $\quad \begin{array}{llllllll}1 & 2 & 3 & 4 & 5 & 6\end{array}$ are contrary to the general consensus.

$\begin{aligned} & \text { 10. It's difficult for me to voice my own opinions } \\ & \text { on controversial matters. }\end{aligned}$
a

11. I often change my mind about decisions if my $\quad \begin{array}{llllllll}1 & 2 & 3 & 4 & 5 & 6\end{array}$ friends or family disagree.

$\begin{aligned} & \text { 12. I am not the kind of person who gives in to } \\ & \text { social pressures to think or act in certain ways. }\end{aligned}$
$\begin{aligned} & \text { 13. I am concerned about how other people } \\ & \text { evaluate the choices I have made in my life. }\end{aligned}$
$\begin{aligned} & \text { 14. I judge myself by what I think is important, } \\ & \text { not by the values of what others think is } \\ & \text { important. }\end{aligned}$




\section{ENVIRONMENTAL MASTERY}

\begin{tabular}{cccccc}
$\begin{array}{l}\text { Strongly } \\
\text { Disagree }\end{array}$ & $\begin{array}{c}\text { Moderately } \\
\text { Disagree }\end{array}$ & $\begin{array}{c}\text { Slightly } \\
\text { Disagree }\end{array}$ & $\begin{array}{c}\text { Slightly } \\
\text { Agree }\end{array}$ & $\begin{array}{c}\text { Moderately } \\
\text { Agree }\end{array}$ & $\begin{array}{c}\text { Strongly } \\
\text { Agree }\end{array}$ \\
\hline 1 & 2 & 3 & 4 & 5 & 6
\end{tabular}

1. In general, I feel I am in charge of the situation $\quad \begin{array}{lllllll}1 & 2 & 3 & 4 & 5 & 6\end{array}$ in which I live.

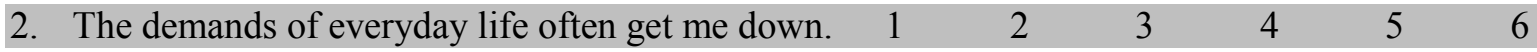

3. I do not fit very well with the people and the $\quad \begin{array}{lllllll}1 & 2 & 3 & 4 & 5 & 6\end{array}$ community around me.

4. I am quite good at managing the many $\quad \begin{array}{lllllll}1 & 2 & 3 & 4 & 5 & 6\end{array}$ responsibilities of my daily life.

5. I often feel overwhelmed by my responsibilities. $\begin{array}{llllllll}1 & 2 & 3 & 4 & 5 & 6\end{array}$

6. If I were unhappy with my living situation, I $\quad \begin{array}{lllllll}1 & 2 & 3 & 4 & 5 & 6\end{array}$ would take effective steps to change it.

7. I generally do a good job of taking care of my $\quad \begin{array}{lllllll}1 & 2 & 3 & 4 & 5 & 6\end{array}$ personal finances and affairs.

8. I find it stressful that I can't keep up with all of $\quad \begin{array}{lllllll}1 & 2 & 3 & 4 & 5 & 6\end{array}$ the things I have to do each day.

9. I am good at juggling my time so that I can fit $\quad \begin{array}{llllllll}1 & 2 & 3 & 4 & 5 & 6\end{array}$ leverything in that needs to get done.

10. My daily life is busy, but I derive a sense of satisfaction from keeping up with everything.

11. I get frustrated when trying to plan my daily activities because I never accomplish the things

I set out to do.

12. My efforts to find the kind of activities and

$4 \quad 5 \quad 6$ relationships that I need have been quite unsuccessful.

13. I have difficulty arranging my life in a way that $\quad \begin{array}{lllllll}1 & 2 & 3 & 4 & 5 & 6\end{array}$ is satisfying to me.

14. I have been able to build a home and a lifestyle 1 2 3 4 5 that is much to my liking. 
$\underline{\text { PERSONAL GROWTH }}$

\begin{tabular}{cccccc}
$\begin{array}{l}\text { Strongly } \\
\text { Disagree }\end{array}$ & $\begin{array}{c}\text { Moderately } \\
\text { Disagree }\end{array}$ & $\begin{array}{c}\text { Slightly } \\
\text { Disagree }\end{array}$ & $\begin{array}{c}\text { Slightly } \\
\text { Agree }\end{array}$ & $\begin{array}{c}\text { Moderately } \\
\text { Agree }\end{array}$ & $\begin{array}{c}\text { Strongly } \\
\text { Agree }\end{array}$ \\
\hline 1 & 2 & 3 & 4 & 5 & 6
\end{tabular}

1. I am not interested in activities that will expand $\quad \begin{array}{lllllll}1 & 2 & 3 & 4 & 5 & 6\end{array}$ my horizons.

$\begin{aligned} & \text { 2. In general, I feel that I continue to learn more } \\ & \text { about myself as time goes by. }\end{aligned}$
$\begin{aligned} & \text { 3. I am the kind of person who likes to give new } \\ & \text { things a try. }\end{aligned}$
4. I don't want to try new ways of doing things -
1
2
3
4
5
6 my life is fine the way it is.

5. I think it is important to have new experiences that challenge how you think about yourself and the world.
6. When I think about it, I haven't really improved much as a person over the years.
7. In my view, people of every age are able to continue growing and developing.

$\begin{array}{llllll}1 & 2 & 3 & 4 & 5 & 6 \\ 1 & 2 & 3 & 4 & 5 & 6\end{array}$

$\begin{array}{llllll}1 & 2 & 3 & 4 & 5 & 6\end{array}$

8. With time, I have gained a lot of insight about life that has made me a stronger, more capable person.

9. I have a sense that I have developed a lot as a person over time.
10. I do not enjoy being in new situations that require $\quad \begin{array}{lllllll}1 & 2 & 3 & 4 & 5 & 6\end{array}$ me to change my old familiar was of doing things.
11. For me, life has been a continuous process of $\quad \begin{array}{llllllll}1 & 2 & 3 & 4 & 5 & 6\end{array}$ learning, changing, and growth.
12. I enjoy seeing how my views have changed and $\quad \begin{array}{lllllll}1 & 2 & 3 & 4 & 5 & 6\end{array}$ matured over the years.
13. I gave up trying to make big improvements or $\quad \begin{array}{llllllll}1 & 2 & 3 & 4 & 5 & 6\end{array}$ changes in my life a long time ago.
14. There is truth to the saying you can't teach an old dog new tricks. 


\section{POSITIVE RELATIONS WITH OTHERS}

\begin{tabular}{cccccc}
$\begin{array}{l}\text { Strongly } \\
\text { Disagree }\end{array}$ & $\begin{array}{c}\text { Moderately } \\
\text { Disagree }\end{array}$ & $\begin{array}{c}\text { Slightly } \\
\text { Disagree }\end{array}$ & $\begin{array}{c}\text { Slightly } \\
\text { Agree }\end{array}$ & $\begin{array}{c}\text { Moderately } \\
\text { Agree }\end{array}$ & $\begin{array}{c}\text { Strongly } \\
\text { Agree }\end{array}$ \\
\hline 1 & 2 & 3 & 4 & 5 & 6
\end{tabular}

1. Most people see me as loving and affectionate. $\quad \begin{array}{llllllll}1 & 2 & 3 & 4 & 5 & 6\end{array}$
2. Maintaining close relationships has been
12 difficult and frustrating for me.

3. I often feel lonely because I have few close friends with whom to share my concerns.

$\begin{array}{lllllll}1 & 2 & 3 & 4 & 5 & 6\end{array}$

4. I enjoy personal and mutual conversations

$\begin{array}{llll}1 & 2 & 3 & 4\end{array}$
with family members or friends.

5. It is important to me to be a good listener when $\quad \begin{array}{llllllll}1 & 2 & 3 & 4 & 5 & 6\end{array}$ close friends talk to me about their problems.
6. I don't have many people who want to listen when I need to talk.

$\begin{array}{llllll}1 & 2 & 3 & 4 & 5 & 6\end{array}$

7. I feel like I get a lot out of my friendships. $\quad \begin{array}{llllllll}1 & 2 & 3 & 4 & 5 & 6\end{array}$
8. It seems to me that most other people have more friends than I do.

$\begin{array}{llllll}1 & 2 & 3 & 4 & 5 & 6\end{array}$

9. People would describe me as a giving person, $\quad \begin{array}{llllllll}1 & 2 & 3 & 4 & 5 & 6\end{array}$ willing to share my time with others.
10. I have not experienced many warm and $\quad \begin{array}{lllllll}1 & 2 & 3 & 4 & 5 & 6\end{array}$ trusting relationships with others.

11. I often feel like I'm on the outside looking $\quad \begin{array}{llllllll} & 1 & 2 & 3 & 4 & 5 & 6\end{array}$ in when it comes to friendships.

$\begin{aligned} & \text { 12. I know that I can trust my friends, and } \\ & \text { they know they can trust me. }\end{aligned}$
$\begin{aligned} & \text { 13. I find it difficult to really open up when I } \\ & \text { talk with others. }\end{aligned}$
$\begin{aligned} & \text { 14. My friends and I sympathize with each } \\ & \text { other's problems. }\end{aligned}$


PURPOSE IN LIFE

\begin{tabular}{cccccc}
$\begin{array}{l}\text { Strongly } \\
\text { Disagree }\end{array}$ & $\begin{array}{c}\text { Moderately } \\
\text { Disagree }\end{array}$ & $\begin{array}{c}\text { Slightly } \\
\text { Disagree }\end{array}$ & $\begin{array}{c}\text { Slightly } \\
\text { Agree }\end{array}$ & $\begin{array}{c}\text { Moderately } \\
\text { Agree }\end{array}$ & $\begin{array}{c}\text { Strongly } \\
\text { Agree }\end{array}$ \\
\hline 1 & 2 & 3 & 4 & 5 & 6
\end{tabular}

1. I feel good when I think of what I've done in the $\quad \begin{array}{lllllll}1 & 2 & 3 & 4 & 5 & 6\end{array}$ past and what I hope to do in the future.

2. I live life one day at a time and don't really think $\quad \begin{array}{lllllll}1 & 2 & 3 & 4 & 5 & 6\end{array}$ about the future.

3. I tend to focus on the present, because the future $\quad \begin{array}{llllllll}1 & 2 & 3 & 4 & 5 & 6\end{array}$ nearly always brings me problems.

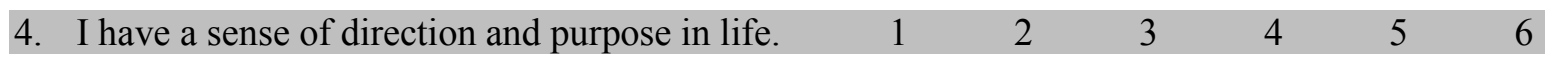

5. My daily activities often seem trivial and $\quad \begin{array}{llllllllll}1 & 2 & 3 & 4 & 5 & 6\end{array}$ unimportant to me.

6. I don't have a good sense of what it is I'm trying $\quad \begin{array}{lllllll}1 & 2 & 3 & 4 & 5 & 6\end{array}$ to accomplish in life.

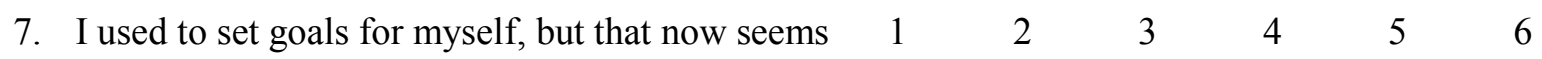
like a waste of time.

8. I enjoy making plans for the future and working $\quad \begin{array}{lllllll}1 & 2 & 3 & 4 & 5 & 6\end{array}$ to make them a reality.

9. I am an active person in carrying out the plans $\quad \begin{array}{lllllllll}1 & 2 & 3 & 4 & 5 & 6\end{array}$ I set for myself.

10. Some people wander aimlessly through life, but $\quad \begin{array}{lllllll}1 & 2 & 3 & 4 & 5 & 6\end{array}$ I am not one of them.

11. I sometimes feel as if I've done all there is to do $\quad \begin{array}{llllllll} & 1 & 2 & 3 & 4 & 5 & 6\end{array}$ in life.

12. My aims in life have been more a source of $\quad \begin{array}{lllllll}1 & 2 & 3 & 4 & 5 & 6\end{array}$ satisfaction than frustration to me.

13. I find it satisfying to think about what I have $\quad \begin{array}{lllllllll}1 & 2 & 3 & 4 & 5 & 6\end{array}$ accomplished in life.
14. In the final analysis, I'm not so sure that my life adds up to much. 
$\underline{\text { SELF-ACCEPTANCE }}$

\begin{tabular}{cccccc}
$\begin{array}{c}\text { Strongly } \\
\text { Disagree }\end{array}$ & $\begin{array}{c}\text { Moderately } \\
\text { Disagree }\end{array}$ & $\begin{array}{c}\text { Slightly } \\
\text { Disagree }\end{array}$ & $\begin{array}{c}\text { Slightly } \\
\text { Agree }\end{array}$ & $\begin{array}{c}\text { Moderately } \\
\text { Agree }\end{array}$ & $\begin{array}{c}\text { Strongly } \\
\text { Agree }\end{array}$ \\
\hline 1 & 2 & 3 & 4 & 5 & 6
\end{tabular}

1. When I look at the story of my life, I am pleased $\quad \begin{array}{llllllll}1 & 2 & 3 & 4 & 5 & 6\end{array}$ with how things have turned out.

2. In general, I feel confident and positive about $\quad \begin{array}{lllllll}1 & 2 & 3 & 4 & 5 & 6\end{array}$ myself.

3. I feel like many of the people I know have $\quad \begin{array}{llllllll}1 & 2 & 3 & 4 & 5 & 6\end{array}$ gotten more out of life than I have.

4. Given the opportunity, there are many things $\quad \begin{array}{lllllll}1 & 2 & 3 & 4 & 5 & 6\end{array}$ about myself I would change.

5. I like most aspects of my personality. $\quad \begin{array}{llllllll} & 1 & 2 & 3 & 4 & 5 & 6\end{array}$

6. I made some mistakes in the past, but I feel that $\quad \begin{array}{lllllll}1 & 2 & 3 & 4 & 5 & 6\end{array}$ all in all everything has worked out for the best.

7. In many ways, I feel disappointed about my $\quad \begin{array}{llllllll}1 & 2 & 3 & 4 & 5 & 6\end{array}$ achievements in life.

8. For the most part, I am proud of who I am and $\quad \begin{array}{lllllll}1 & 2 & 3 & 4 & 5 & 6\end{array}$ the life I lead.

9. I envy many people for the lives they lead. $\quad \begin{array}{lllllllll}1 & 2 & 3 & 4 & 5 & 6\end{array}$

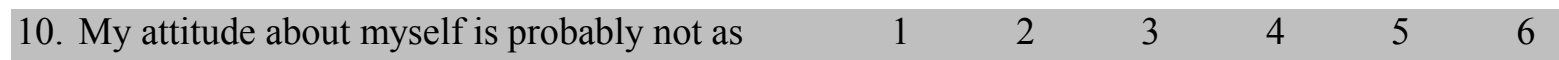
positive as most people feel about themselves.

11. Many days I wake up feeling discouraged about $\quad \begin{array}{llllllll}1 & 2 & 3 & 4 & 5 & 6\end{array}$ how I have lived my life.

12. The past had its ups and downs, but in general, $\quad \begin{array}{lllllll}1 & 2 & 3 & 4 & 5 & 6\end{array}$ I wouldn't want to change it.

13. When I compare myself to friends and acquaintances, it makes me feel good about who I am.

14. Everyone has their weaknesses, but I seem to have more than my share. 


\section{Appendix I}

\section{Social Connectedness Scale - Revised}

Instructions: The following are a number of statements that reflect various ways in which we view ourselves. Rate the degree to which you agree or disagree with each statement using the following scale ( $1=$ Strongly Disagree and $6=$ Strongly Agree). There is no right or wrong answer. Do not spend too much time with any one statement and do not leave any unanswered.

\begin{tabular}{cccccc}
$\begin{array}{c}\text { Strongly } \\
\text { Disagree }\end{array}$ & Disagree & $\begin{array}{c}\text { Mildly } \\
\text { Disagree }\end{array}$ & $\begin{array}{c}\text { Mildly } \\
\text { Agree }\end{array}$ & Agree & $\begin{array}{c}\text { Strongly } \\
\text { Agree }\end{array}$ \\
\hline 1 & 2 & 3 & 4 & 5 & 6
\end{tabular}

1. I feel comfortable in the presence of strangers. $\begin{array}{lllllllll}1 & 2 & 3 & 4 & 5 & 6\end{array}$

2. I am in tune with the world. $\quad 1 \quad \begin{array}{llllll} & 2 & 3 & 4 & 5 & 6\end{array}$

3. Even among my friends, there is no sense of $\begin{array}{lllllllll}\text { brother/sisterhood. } & 1 & 2 & 3 & 4 & 5 & 6\end{array}$

4. I fit in well in new situations. $\quad 1 \quad \begin{array}{llllll} & 2 & 3 & 4 & 5 & 6\end{array}$

$\begin{array}{llllllll}\text { 5. I feel close to people. } & 1 & 2 & 3 & 4 & 5 & 6\end{array}$

6. I feel disconnected from the world around me. $\begin{array}{lllllll}1 & 2 & 3 & 4 & 5 & 6\end{array}$

7. Even around people I know, I don't feel that I $\begin{array}{lllllllll}\text { really belong. } & 1 & 2 & 3 & 4 & 5 & 6\end{array}$

8. I see people as friendly and approachable. $\quad \begin{array}{llllllll}1 & 2 & 3 & 4 & 5 & 6\end{array}$

9. I feel like an outsider. $\quad \begin{array}{lllllll} & 1 & 2 & 3 & 4 & 5 & 6\end{array}$

10. I feel understood by the people I know. $\quad \begin{array}{lllllll}1 & 2 & 3 & 4 & 5 & 6\end{array}$

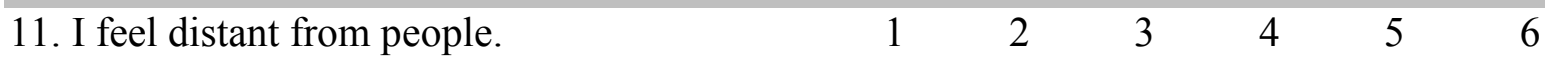

$\begin{array}{llllllll}\text { 12. I am able to relate to my peers. } & 1 & 2 & 3 & 4 & 5 & 6\end{array}$

13. I have little sense of togetherness with $\begin{array}{llllllll}\text { my peers. } & 1 & 2 & 3 & 4 & 5 & 6\end{array}$

14. I find myself actively involved in $\quad \begin{array}{llllllll}1 & 2 & 3 & 4 & 5 & 6\end{array}$
people's lives. 


\begin{tabular}{cccccc}
$\begin{array}{c}\text { Strongly } \\
\text { Disagree }\end{array}$ & Disagree & $\begin{array}{c}\text { Mildly } \\
\text { Disagree }\end{array}$ & $\begin{array}{c}\text { Mildly } \\
\text { Agree }\end{array}$ & Agree & $\begin{array}{c}\text { Strongly } \\
\text { Agree }\end{array}$ \\
\hline 1 & 2 & 3 & 4 & 5 & 6
\end{tabular}

15. I catch myself losing a sense of $\quad \begin{array}{lllllll} & 1 & 2 & 3 & 4 & 5 & 6\end{array}$ connectedness with society.

16. I am able to connect with other people. $\quad \begin{array}{lllllll}1 & 2 & 3 & 4 & 5 & 6\end{array}$

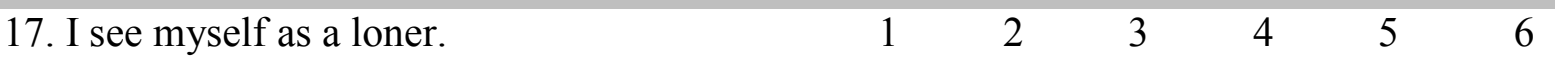

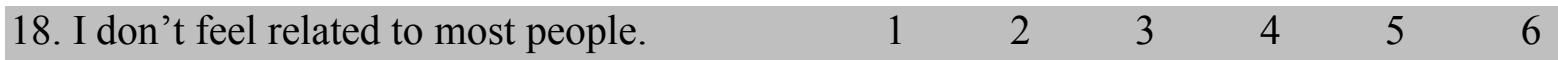

19. My friends feel like family. $\quad \begin{array}{lllllll}1 & 2 & 3 & 4 & 5 & 6\end{array}$

20. I don't feel I participate with anyone or $\quad \begin{array}{lllllll}1 & 2 & 3 & 4 & 5 & 6\end{array}$ any group. 


\section{Appendix J}

\section{Social Provisions Scale - General Version}

Instructions: In answering the following questions, think about your current relationships with friends, family members, co-workers, community members, and so on. Please indicate to what extent each statement describes your current relationship with other people. Use the following sale to indicate your opinion.

\begin{tabular}{cccc}
$\begin{array}{l}\text { Strongly } \\
\text { Disagree }\end{array}$ & Disagree & Agree & $\begin{array}{c}\text { Strongly } \\
\text { Agree }\end{array}$ \\
\hline 1 & 2 & 3 & 4
\end{tabular}

So, for example, if you feel a statement is very true of your current relationships, you would respond with a 4 (strongly agree). If you feel a statement clearly does not describe your relationships, you would respond with a 1 (strongly disagree).

\begin{tabular}{|c|c|c|c|c|}
\hline 1. There are people I can depend on to help me if I really need it. & 1 & 2 & 3 & 4 \\
\hline $\begin{array}{l}\text { 2. I feel that I do not have close personal relationships with other } \\
\text { people. }\end{array}$ & 1 & 2 & 3 & 4 \\
\hline 3. There is no one I can turn to for guidance in times of stress. & 1 & 2 & 3 & 4 \\
\hline 4. There are people who depend on me for help. & 1 & 2 & 3 & 4 \\
\hline 5. There are people who enjoy the same social activities I do. & 1 & 2 & 3 & 4 \\
\hline 6. Other people do not view me as competent. & 1 & 2 & 3 & 4 \\
\hline $\begin{array}{l}\text { 7. I feel personally responsible for the well-being of another } \\
\text { person. }\end{array}$ & 1 & 2 & 3 & 4 \\
\hline $\begin{array}{l}\text { 8. I feel part of a group of people who share my attitudes and } \\
\text { beliefs. }\end{array}$ & 1 & 2 & 3 & 4 \\
\hline 9. I do not think of other people respect my skills and abilities. & 1 & 2 & 3 & 4 \\
\hline 10. If something went wrong, no one would come to my assistance. & 1 & 2 & 3 & 4 \\
\hline $\begin{array}{l}\text { 11. I have close relationships that provide me with a sense of } \\
\text { emotional security and well-being. }\end{array}$ & 1 & 2 & 3 & 4 \\
\hline $\begin{array}{l}\text { 12. There is someone I could talk to about important decisions in my } \\
\text { life. }\end{array}$ & 1 & 2 & 3 & 4 \\
\hline $\begin{array}{l}\text { 13. I have relationships where my competence and skill are } \\
\text { recognized. }\end{array}$ & 1 & 2 & 3 & 4 \\
\hline 14. There is no one who shares my interests and concerns. & 1 & 2 & 3 & 4 \\
\hline 15. There is no one who really relies on me for their well-being. & 1 & 2 & 3 & 4 \\
\hline $\begin{array}{l}\text { 16. There is a trustworthy person I could turn to for advice if I were } \\
\text { having problems. }\end{array}$ & 1 & 2 & 3 & 4 \\
\hline 17. I feel a strong emotional bond with at least one other person. & 1 & 2 & 3 & 4 \\
\hline 18. There is no one I can depend on for aid if I really need it. & 1 & 2 & 3 & \\
\hline 19. There is no one I feel comfortable talking about problems with. & 1 & 2 & 3 & 4 \\
\hline 20. There are people who admire my talents and abilities & 1 & 2 & 3 & 4 \\
\hline 21. I lack a feeling of intimacy with another person. & 1 & 2 & 3 & 4 \\
\hline 22. There is no one who lies to do things I do. & 1 & 2 & 3 & \\
\hline 23. There are people who I can count on in an emergency. & 1 & 2 & 3 & 4 \\
\hline 24. No one needs me to care for them. & 1 & 2 & 3 & 4 \\
\hline
\end{tabular}




\section{Appendix K}

\section{Unsupportive Social Interactions Inventory (USII)}

Please think about times you've turned to your friends for support in regards to a situation that was bothering you (i.e. frustrations or disappointments with friends, family, school, health, work or anything else that is important to you). For each of the statements below, please circle the number that indicates how frequently your friends responded in this way when you went to them for support.

None

A lot

1. Would not seem to want to hear about it.

$\begin{array}{lllll}0 & 1 & 2 & 3 & 4\end{array}$

2. Would refuse to take me seriously.

$\begin{array}{lllll}0 & 1 & 2 & 3 & 4\end{array}$

3. Would change the subject before I wanted to.

$\begin{array}{lllll}0 & 1 & 2 & 3 & 4\end{array}$

4. Would refuse to provide the type of help or support I was asking for.

5. When I was talking about it, the person wouldn't give me enough $\quad \begin{array}{lllllll}0 & 1 & 2 & 3 & 4\end{array}$ time, or would make me feel like I should hurry.

6. Would discourage me from expressing feelings such as anger, hurt or $\quad \begin{array}{lllllll}0 & & 1 & 2 & 3 & 4\end{array}$ sadness.

7. Would not seem to know what to say, or would seem afraid of saying $\quad \begin{array}{lllllll}0 & 1 & 2 & 3 & 4\end{array}$ or doing the "wrong" thing.

8. Would seem to be telling me what he or she thought I wanted to hear. $\quad \begin{array}{llllll}0 & 1 & 2 & 3 & 4\end{array}$

9. From voice tone, expression, or body language, I would get the feeling $\quad \begin{array}{llllll}0 & 1 & 2 & 3 & 4\end{array}$ he or she was uncomfortable talking about it.

10. Would try to cheer me up when I was not ready to. $\quad \begin{array}{lllll}0 & 1 & 2 & 3 & 4\end{array}$

11. Would respond with uninvited physical touching (e.g., hugging). $\quad \begin{array}{llllll}0 & 1 & 2 & 3 & 4\end{array}$

12. Would do things for me that I would want to do and could do myself. $\quad \begin{array}{llllll}0 & 1 & 2 & 3 & 4\end{array}$

13. Would feel that I should stop worrying about the event and just forget $\quad \begin{array}{llllll}0 & 1 & 2 & 3 & 4\end{array}$ about it.

14. Would tell me to be strong, to keep my chin up, or that I should not let $\quad \begin{array}{llllll}0 & 1 & 2 & 3 & 4\end{array}$ it bother me.

15. Would feel that I should focus on the present or the future and that $I$

$\begin{array}{lllll}0 & 1 & 2 & 3 & 4\end{array}$
should forget about what has happened and get on with my life. 
None A lot

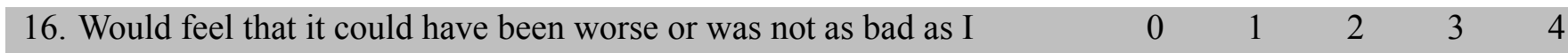
thought.

17. Would say that I should look on the bright side.

$\begin{array}{lllll}0 & 1 & 2 & 3 & 4\end{array}$

18. Would feel that I was overreacting.

$\begin{array}{lllll}0 & 1 & 2 & 3 & 4\end{array}$

19. Would ask "why" questions about my role in the event.

$\begin{array}{lllll}0 & 1 & 2 & 3 & 4\end{array}$

20. Would make "Should or shouldn't have" comments about my role in $\quad \begin{array}{llllll}0 & 1 & 2 & 3 & 4\end{array}$ the event.

21. Would tell me that I had gotten myself into the situation in the first place, and now must deal with the consequences.

22. Would blame me, or try to make me feel responsible for the event

$\begin{array}{lllll}0 & 1 & 2 & 3 & 4\end{array}$

23. Would make "I told you so" or similar comments.

0

0

1

2
24. Would seem to be disappointed in me.
0
12
34

Please think about times you've turned to your parents for support in regards to a situation that was bothering you (i.e. frustrations or disappointments with friends, family, school, health, work or anything else that is important to you). For each of the statements below, please circle the number that indicates how frequently your parents responded in this way when you went to them for support.

None

A lot

1. Would not seem to want to hear about it. $\begin{array}{lllll}0 & 1 & 2 & 3 & 4\end{array}$

2. Would refuse to take me seriously.

0

3. Would change the subject before I wanted to.

$\begin{array}{lllll}0 & 1 & 2 & 3 & 4\end{array}$

4. Would refuse to provide the type of help or support I was asking for.

$\begin{array}{lllll}0 & 1 & 2 & 3 & 4 \\ 0 & 1 & 2 & 3 & 4\end{array}$

5. When I was talking about it, the person wouldn't give me enough time, or would make me feel like I should hurry.
6. Would discourage me from expressing feelings such as anger, hurt or $\quad \begin{array}{lllllll}0 & & 1 & 2 & 3 & 4\end{array}$ sadness.

7. Would not seem to know what to say, or would seem afraid of saying

0
or doing the "wrong" thing. 
None A lot

8. Would seem to be telling me what he or she thought I wanted to hear. $\quad \begin{array}{lllllll}0 & 1 & 2 & 3 & 4\end{array}$

9. From voice tone, expression, or body language, I would get the feeling $\begin{array}{lllllll}0 & 1 & 2 & 3 & 4\end{array}$ he or she was uncomfortable talking about it.

10. Would try to cheer me up when I was not ready to. $\quad \begin{array}{lllllll}0 & 1 & 2 & 3 & 4\end{array}$

11. Would respond with uninvited physical touching (e.g., hugging). $\quad \begin{array}{llllllll}0 & & 1 & 2 & 3 & 4\end{array}$

12. Would do things for me that I would want to do and could do myself. $\quad \begin{array}{lllllll}0 & 1 & 2 & 3 & 4\end{array}$

13. Would feel that I should stop worrying about the event and just forget $\begin{array}{lllllll}0 & 1 & 2 & 3 & 4\end{array}$ about it.

14. Would tell me to be strong, to keep my chin up, or that I should not let $\quad \begin{array}{lllllll}0 & 1 & 2 & 3 & 4\end{array}$ it bother me.

15. Would feel that I should focus on the present or the future and that I $\quad \begin{array}{llllllll}0 & 1 & 2 & 3 & 4\end{array}$ should forget about what has happened and get on with my life.

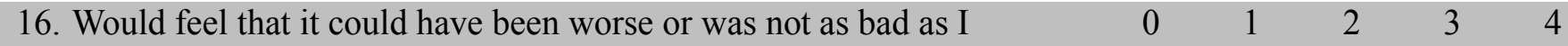
thought.

17. Would say that I should look on the bright side.

$\begin{array}{lllll}0 & 1 & 2 & 3 & 4\end{array}$

18. Would feel that I was overreacting. $\quad \begin{array}{llllll}0 & 1 & 2 & 3 & 4\end{array}$

19. Would ask "why" questions about my role in the event. $\quad \begin{array}{lllllll}0 & 1 & 2 & 3 & 4\end{array}$

20. Would make "Should or shouldn't have" comments about my role in $\quad \begin{array}{lllllll}0 & 1 & 2 & 3 & 4\end{array}$ the event.

21. Would tell me that I had gotten myself into the situation in the first $\quad \begin{array}{lllllll}0 & 1 & 2 & 3 & 4\end{array}$ place, and now must deal with the consequences.

22. Would blame me, or try to make me feel responsible for the event. $\quad \begin{array}{lllllll}0 & 1 & 2 & 3 & 4\end{array}$

23. Would make "I told you so" or similar comments.

$\begin{array}{lllll}0 & 1 & 2 & 3 & 4\end{array}$

24. Would seem to be disappointed in me.

$\begin{array}{lllll}0 & 1 & 2 & 3 & 4\end{array}$




\section{Appendix L}

\section{UCLA Loneliness Scale (Version 3)}

\begin{tabular}{cccc} 
Never & Rarely & Sometimes & Always \\
\hline 1 & 2 & 3 & 4
\end{tabular}

1. How often do you feel that you are "in tune" with the people

$\begin{array}{llll}1 & 2 & 3 & 4\end{array}$
around you?

2. How often do you feel that you lack companionship?

3. How often do you feel that there is no one you can turn to?

\section{How often do you feel alone?}

5. How often do you feel part of a group of friends?
6. How often do you feel that you have a lot in common with the $\quad \begin{array}{lllll}1 & 2 & 3 & 4\end{array}$ people around you?

7. How often do you feel that you are no longer close to anyone?
8. How often do you feel that your interests and ideas are not shared $\begin{array}{llllll}1 & 2 & 3 & 4\end{array}$ by those around you?

9. How often do you feel outgoing and friendly? $\quad \begin{array}{lllll}1 & 2 & 3 & 4\end{array}$

10. How often do you feel close to people? $\quad \begin{array}{lllll}1 & 2 & 3 & 4\end{array}$

$\begin{array}{lllllll}\text { 11. How often do you feel left out? } & 1 & 2 & 3 & 4\end{array}$

12. How often do you feel that your relationships with others are not $\quad \begin{array}{lllll}1 & 2 & 3 & 4\end{array}$ meaningful?

\begin{tabular}{|c|c|c|c|c|}
\hline 13. How often do you feel that no one really knows you well? & 1 & 2 & 3 & 4 \\
\hline 14. How often do you feel isolated from others? & 1 & 2 & 3 & 4 \\
\hline 15. How often do you feel you can find companionship when you want & 1 & 2 & 3 & 4 \\
\hline
\end{tabular}
it?

$\begin{aligned} & \text { 16. How often do you feel that there are people who really understand } \\ & \text { you? }\end{aligned}$
$\begin{array}{llllll}\text { 17. How often do you feel shy? } & 2 & 3 & 4 \\ \text { 18. How often do you feel that people are around you but not with you? } & 1 & 2 & 3 & 4 \\ \text { 19. How often do you feel that there are people you can talk to? } & 1 & 2 & 3 & 4 \\ \text { 20. How often do you feel that there are people you can turn to? } & 1 & 2 & 3 & 4\end{array}$

21. If you feel lonely, how long have you been feeling this way? I'm not lonely;

OR please specify: for the past days; OR months; OR years 